\title{
MULTIPERIOD SUPPLY CHAIN NETWORK EQUILIBRIUM MODEL WITH ELECTRONIC COMMERCE AND MULTICRITERIA DECISION-MAKING *,**
}

\author{
Guoshan LiU ${ }^{1}$ And ShiqIn Xu ${ }^{2}$
}

\begin{abstract}
In this paper, we develop a supply chain network equilibrium model in which electronic commerce in the presence of both B2B (business-to-business) and B2C (business-to-consumer) transactions, multiperiod decision-making and multicriteria decision-making are integrated. The model consists of three tiers of decision-makers (manufacturers, retailers and consumers at demand markets) who compete within a tier but may cooperate between tiers. Both manufacturers and retailers are concerned with maximization of profit as well as minimization of risk, whereas consumers take both the prices charged by manufacturers and retailers, along with the corresponding costs of transacting, in making their consumption decisions. Increasing relationship levels are assumed to decrease costs of transacting as well as risk costs. Establishing and maintaining these relationship levels incur some costs that have to be borne by the various decision-makers. We study the interaction among different tiers of decision-makers, describe their multicriteria decision-making behavior and derive the optimality conditions as well as the equilibrium conditions which are then shown to satisfy a finite-dimensional variational inequality problem. We then establish qualitative properties of the equilibrium model under some reasonable assumptions and illustrate the model with several numerical examples.
\end{abstract}

Received August 28, 2011. Accepted June 14, 2012.

* This research is supported by Nature Science Foundation of China (NSFC) Grant No. 11171348.

** Special thanks are addressed to the two anonymous Reviewers as well as the Editor for valuable comments and helpful suggestions. The authors would like to thank Professor Jiye Han for his helpful advice.

1 School of Business, Renmin University of China, Beijing 100872, P.R. China.

2 Corresponding Author, School of Business, Renmin University of China, Beijing 100872,

P.R. China. xushiqin85@126.com 
Keywords. Supply chain, network equilibrium, electronic commerce, multiperiod decision-making, multicriteria decision-making, variational inequality.

Mathematics Subject Classification. 49J40, 90B06, 91A40.

\section{INTRODUCTION}

With the development of the Internet and innovations in technology, the availability of electronic commerce (e-commerce) via the Internet has had a tremendous effect on the manner in which the physical ordering of goods is replaced by electronic orders in the form of business-to-business (B2B) commerce and businessto-consumer (B2C) commerce. In addition, the introduction of e-commerce had opened up new opportunities for the management of supply chain networks ( $c f$. Nagurney and Dong [20], Kuglin and Rosenbaum [11], and the references therein).

The supply chain is a relationship network which integrates the movements of goods between suppliers, manufacturers, distributors, retailers, and consumers (see [31]). Indeed, supply chain network with e-commerce is a topic of growing interest due to its practical importance. For example, Nagurney et al. [23] developed a supply chain network model with three tiers of decision-makers in the presence of e-commerce, where both B2B and B2C transactions were contained. Nagurney and Toyasaki [26], in turn, developed a supply chain supernetwork model with environmental criteria that also included e-commerce.

It is clear that equilibrium models have a long tradition in transportation modeling as well as in economics ( $c f$. Arrow and Intrilligator [1]). Nagurney et al. [24] proposed the first supply chain network equilibrium model consisting of manufacturers, retailers, and consumers at the demand markets. The supply chain network equilibrium problem was formulated using the variational inequality approach (Nagurney et al., $[23,24]$ ). For an overview of finite-dimensional variational inequality and applications based on network, see the book by Kinderlehrer and Stampacchia [10], Nagurney [17], and the references therein.

The first contributor to the multicriteria decision-making of network was Quandt [30] and a multicriteria traffic network equilibrium modeling could be found in Nagurney and Dong [21] as well as Nagurney [18]. Nagurney et al. [22] developed a multicriteria spatial network model but only the consumers at the demand markets considered multicriteria decision-making. Dong et al. [6], in turn, introduced multicriteria decision-making including the maximization of profit, the minimization of transportation time and the maximization of service level in their supply chain network model. Wakolbinger and Nagurney [33] developed a framework for the modeling and analysis of supply chain network with e-commerce that also included the role that relationship played. Furthermore, Li [12] presented a multicriteria supply chain network with e-commerce, but the model was static. Nagurney et al. [27] proposed a rigorous dynamic supernetwork theory for the 
integration of social networks and financial networks with intermediation in the presence of electronic transactions, where relationship level was used for social networks. Nagurney and Ladimer [25] developed a sustainable supply chain network design model that allowed for the evaluation of environmental multicriteria decision-making. Other applications of multicriteria decision-making in a spatial context can be found in Stewart and Honert [32] and the references therein.

In fact, the supply chain is a typical dynamic system in which the relationship among the various decision-makers is time-varying. Cai [3] had proposed a multiperiod supply chain network equilibrium model in which the time periods over a finite planning horizon was discrete. Li et al. [14] developed a supply chain dynamic network model which was comprised of manufactures and wholesalers who were involved in inventorying along with multiperiod decision-making. In addition, Nagurney and Aronson [19] constructed a multiperiod spatial pricing equilibrium model in which inventorying and backordering were allowed at the supply markets as well as the demand markets. Bernstein and Federgruen [2] studied retail market competition in the case of a single supplier and multiple retailers in a multiperiod setting. More recently, Perakis and Sood [29] developed multiperiod pricing at retail markets using a robust optimization approach. Liu and Nagurney [13] established a multiperiod competitive supply chain network equilibrium model which could be reformulated and solved as a transportation network equilibrium problem. In those models, however, the decision-makers were faced with a single criterion (e.g., profit maximization in the case of manufacturers and retailers) and e-commerce was not considered.

Now, we have obtained three important characteristics (i.e., e-commerce, multicriteria decision-making including profit and risk, and multiperiod decisionmaking) that are all centered on the supply chain network equilibrium model. The relevant references with the above characteristics are briefly summarized and presented in Table 1.

Here, in contrast, we build upon the work of Nagurney et al. [27] and Cai [3] to formulate a theoretical framework of the supply chain network equilibrium with the following notable features:

1. it is concerned with the multicriteria decision-making behavior which includes the maximization of profit as well as the minimization of risk for the manufacturers and the retailers;

2. it considers e-commerce in the model due to its importance in practice. The retailers may be physical or virtual in the case of e-commerce; consumers at different markets can purchase the product from the manufacturers via the Internet;

3. the relationship levels are assumed to be symmetric and establishing them incurs some costs that have to be borne by decision-makers in the network; unlike most of the previous researches, these levels are regarded as factors but they are not relevant to a separated criteria;

4. it includes multiperiod decision-making, that is, decisions involved in inventorying are made in discrete time periods over a finite planning horizon; 
TABLE 1. Summary of the relevant references with different characteristics.

\begin{tabular}{|c|c|c|c|c|c|c|}
\hline & \multirow{2}{*}{$\begin{array}{l}\text { Electronic } \\
\text { commerce }\end{array}$} & \multicolumn{4}{|c|}{ Multicriteria decision-making } & \multirow{2}{*}{$\begin{array}{c}\text { Multiperiod } \\
\text { decision-making }\end{array}$} \\
\hline & & profit & risk & relationship & other & \\
\hline $\begin{array}{l}\text { Nagurney } \\
\text { et al. }(2002)\end{array}$ & $\sqrt{ }$ & $\sqrt{ }$ & & & & \\
\hline $\begin{array}{l}\text { Dong et al. } \\
(2002)\end{array}$ & $\sqrt{ }$ & $\sqrt{ }$ & & & $\sqrt{ }$ & \\
\hline $\begin{array}{l}\text { Nagurney and } \\
\text { Toyasaki (2004) }\end{array}$ & $\sqrt{ }$ & $\sqrt{ }$ & & & $\sqrt{ }$ & \\
\hline $\mathrm{Li}(2007)$ & $\sqrt{ }$ & $\sqrt{ }$ & $\sqrt{ }$ & $\sqrt{ }$ & & \\
\hline $\begin{array}{l}\text { Wakolbinger and } \\
\text { Nagurney (2004) }\end{array}$ & $\sqrt{ }$ & $\sqrt{ }$ & $\sqrt{ }$ & $\sqrt{ }$ & & \\
\hline $\begin{array}{l}\text { Nagurney et al. } \\
(2006)\end{array}$ & $\sqrt{ }$ & $\sqrt{ }$ & & $\sqrt{ }$ & & \\
\hline $\begin{array}{l}\text { Nagurney and } \\
\text { Ladimer (2010) }\end{array}$ & $\sqrt{ }$ & $\sqrt{ }$ & & & $\sqrt{ }$ & \\
\hline Cai (2003) & & $\sqrt{ }$ & & & & $\sqrt{ }$ \\
\hline $\begin{array}{l}\text { Li et al. } \\
(2006)\end{array}$ & & $\sqrt{ }$ & & & & $\sqrt{ }$ \\
\hline $\begin{array}{l}\text { Nagurney and } \\
\text { Aronson (1988) }\end{array}$ & & $\sqrt{ }$ & & & & $\sqrt{ }$ \\
\hline $\begin{array}{l}\text { Liu and } \\
\text { Nagurney (2012) }\end{array}$ & & $\sqrt{ }$ & & & & $\sqrt{ }$ \\
\hline This paper & $\sqrt{ }$ & $\sqrt{ }$ & $\sqrt{ }$ & $\sqrt{ }$ & & $\sqrt{ }$ \\
\hline
\end{tabular}

5. it formalizes the incorporation of relationship levels which are assumed to reduce the risk costs and the costs of transacting at the following time period but not the current one;

6. it allows for solution of the equilibrium product flows and prices for some managerial insights generated from the model or the numerical examples.

The paper is organized as follows. In Section 1, we describe the behavior of the various decision-makers, develop the multiperiod supply chain equilibrium model with e-commerce and multicriteria decision-making, and then establish the governing equilibrium conditions along with the corresponding variational inequality formulation. In Section 2, we use the variational inequality formulation to obtain qualitative properties regarding the existence as well as the uniqueness of the equilibrium model under some reasonable conditions. Subsequently, in Section 3, several numerical examples are presented for illustration purposes and discussed for some managerial insights. Finally, we conclude the paper with Section 4, in which we summarize our results obtained in this paper and provide suggestions for future research. 


\section{The FORMulation of The MOdel StRuCture}

In this section, we develop the multiperiod supply chain network equilibrium model with manufacturers, retailers, and consumers at demand markets in which we explicitly synthesize e-commerce, risk and relationship levels between buyers and sellers. The whole supply chain is assumed to be a non-cooperative and competitive network structure, and then, the governing equilibrium conditions can be formulated as a variational inequality (see Nagurney [16]). Specifically, we assume that the demand function at each demand market is deterministic.

As the previous relevant papers use "transaction cost" in the process of modeling almost without exception, it is necessary to define it in our paper. The term, "transaction cost" (Coase [4], Williamson [34]) included the cost of searching business partners, the cost of the negotiations between the trading partners and the costs of achieving the transaction. Compared with the traditional mode, it is accepted that the e-commerce does reduce the corresponding transaction cost (Lucking-Reiley and Spulber [15]). Maybe there are minor essential differences in the structure of transaction cost between electronic and non-electronic modes, but the former has a cost advantage over the latter. In contrast, there may be none advantage for electronic transactions in the way of decreasing the delivery cost. In particular, even though a retailer is virtual and the transaction takes place electronically, the product is to be delivered physically.

In the work of Nagurney et al. [24], they considered that the transaction cost was sufficiently general, for example, to include the transportation/shipping cost. They also held that, in the case of an e-commerce link, the transaction costs could include the cost associated with the use of such a link, congestion, etc. However, we take a broader definition here, namely, the "cost of transacting" is solely the broader definition of "transaction cost". We define it as the cost that covers the whole process including the preparation prior to purchase, the distribution and delivery during transactions and monitoring after transactions. That is to say the cost of transacting is composed of the transaction cost from Coase and the corresponding delivery cost, which is assumed to be reduced with the increase of relationship level.

As the risk in the model, from Cruz [5], it was defined as the possibility for companies to suffer harm or loss for their activities and also for the activities of their partners in the supply chain. Furthermore, Juttner et al. [9] suggested that supply chain-relevant risk sources fall into three categories, that is, environmental risk sources, organizational risk sources and network-related risk sources. Johnson [8] and Norrman and Jansson [28] held that network-related risk was caused by the interaction between organizations within the supply chain, e.g., due to insufficient interaction and cooperation. Here, we define the risk in the multiperiod supply chain equilibrium model as the risks within the supply chain and as the functions of both the product transactions and relationship levels. High relationship levels are assumed to reduce risk because trust decreases transactional uncertainty (see [12, 27,33]). 




FigurE 1. The structure of the multiperiod supply chain network.

The activities in the supply chain network include manufacturing, shipment, distribution, storage, and, ultimately, selling of the product to the consumers at different demand markets. The model considers $M$ manufacturers involved in the production of a homogeneous product, who can sell directly to $K$ demand markets through the Internet (links represented by dotted arcs in Fig. 1) and can also conduct their transactions with $J$ retailers through the Internet (links represented by dashed arcs in Fig. 1) or physically (links represented by solid arrows in Fig. 1). The retailers can be either physical or virtual as in the case of e-commerce and they are assumed to transact physically (links represented by solid arrows in Fig. 1) with consumers.

We denote a typical manufacturer by $i$, a typical retailer by $j$, and a typical demand market by $k$, respectively. We let $l$ denote the type of transaction with $l=1$ representing a physical transaction and $l=2$ denoting a virtual transaction via the Internet. Moreover, the time planning horizon is discretized into $T$ periods with a typical period by $t$. It is assumed that the discreted value of the notation $t$ emerging in the paper ranges from 1 to $T$, namely, $t=\{1,2, \ldots, T\}$, except where noted otherwise.

The top-tiered nodes in Figure 1 represent the manufacturers in the $T$ time periods with node $i(t)$ denoting manufacturer $i$ at time period $t$. A node $j(t)$ corresponds to retailer $j$ at time period $t$. Manufacturer $i$ can store the product as his inventory between time period $t$ and time period $(t+1)$ with a link joining node $i(t)$ to node $i(t+1)$. Retailer $j$ can also store some product as the manufacturers do with a link joining node $j(t)$ to node $j(t+1)$ corresponding to his inventory from time period $t$ to time period $(t+1)$. The consumers at different demand markets are represented by the node $k(t)$ in the bottom tier of the supply chain network. The decision variables associated with the manufacturers and the retailers are defined in Tables 2 and 4, respectively. Moreover, the majority of the cost functions related to the model are given in Tables 3 and 5 . The equilibrium solution is marked by "*".

In this section, we develop the multiperiod supply chain network model with manufacturers, retailers and consumers located at the demand markets. 
TABLE 2. Decision variables of the manufacturers in multiperiod supply chain network equilibrium model.

\begin{tabular}{|c|c|}
\hline $\begin{array}{l}\text { Decision } \\
\text { variables }\end{array}$ & Definition \\
\hline$q_{i}^{t}$ & production output of manufactureriat time period $t$ \\
\hline$q^{t}$ & $\begin{array}{l}I \text {-dimensional column vector grouped by production outputs for all } \\
\text { manufacturers at time period } t \text { with component } q_{i}^{t}\end{array}$ \\
\hline$q$ & $\begin{array}{l}I T \text {-dimensional column vector grouped by production outputs for all } \\
\text { manufacturers during the entire planning horizon with component } q_{i}^{t}\end{array}$ \\
\hline$q_{i j l}^{t}$ & $\begin{array}{l}\text { product shipments transacted with retailer } j \text { by manufacturer } i \text { via } \\
\text { model at time period } t\end{array}$ \\
\hline$\overline{Q_{1}^{t}}$ & $\begin{array}{l}2 I J \text {-dimensional column vector grouped by shipments transacted be- } \\
\text { tween manufacturers and retailers with component } q_{i j l}^{t}\end{array}$ \\
\hline$Q_{1}$ & $\begin{array}{l}2 I J T \text {-dimensional column vector grouped by shipments transacted be- } \\
\text { tween manufacturers and retailers during the entire planning horizon } \\
\text { with component } q_{i j l}^{t}\end{array}$ \\
\hline$q_{i k}^{t}$ & $\begin{array}{l}\text { product shipments from manufacturer } i \text { to demand market } k \text { via the } \\
\text { Internet at time period } t\end{array}$ \\
\hline$Q_{2}^{t}$ & $\begin{array}{l}I K \text {-dimensional column vector grouped by product flows between man- } \\
\text { ufacturers and demand markets at time period } t \text { with component } q_{i k}^{t}\end{array}$ \\
\hline$Q_{2}$ & $\begin{array}{l}I K T \text {-dimensional column vector grouped by product flows between } \\
\text { manufacturers and demand markets during the entire planning hori- } \\
\text { zon with component } q_{i k}^{t}\end{array}$ \\
\hline$I_{i}^{t}$ & inventory quantity of manufacturer $i$ at the end of time period $t$ \\
\hline$Q_{3}^{t}$ & $\begin{array}{l}I \text {-dimensional column vector grouped by inventories of manufacturers } \\
\text { at time period } t \text { with component } I_{i}^{t}\end{array}$ \\
\hline$Q_{3}$ & $\begin{array}{l}\text { IT-dimensional column vector grouped by inventories of manufacturers } \\
\text { during the entire planning horizon with component } I_{i}^{t}\end{array}$ \\
\hline$h_{i j l}^{t}$ & $\begin{array}{l}\text { nonnegative relationship level between manufacturer } i \text { and retailer } j \\
\text { via mode } l \text { at time period } t, t=1,2 \ldots, T-1 ; h_{i j l}^{t}=0 \text { for } t=0, T\end{array}$ \\
\hline$h_{1}^{t}$ & $\begin{array}{l}2 I J \text {-dimensional column vector grouped by nonnegative relationship } \\
\text { level for all manufacturer/retailer } / \text { mode combinations at time period } \\
t, t=1,2 \ldots, T-1 ; h_{1}^{t}=0 \text { for } t=0, T\end{array}$ \\
\hline$h_{1}$ & $\begin{array}{l}2 I J(T+1) \text {-dimensional column vector grouped by nonnegative relation- } \\
\text { ship level for all manufacturer/retailer/mode combinations for } t= \\
0,1 \ldots, T\end{array}$ \\
\hline$h_{i k}^{t}$ & $\begin{array}{l}\text { nonnegative relationship level between manufacturer } i \text { and demand } \\
\text { market } k \text { at time period } t, t=1,2 \ldots, T-1 ; h_{i k}^{t}=0 \text { for } t=0, T\end{array}$ \\
\hline$h_{2}^{t}$ & $\begin{array}{l}I K \text {-dimensional column vector grouped by nonnegative relationship } \\
\text { level for all manufacturer/demand market combinations at time period } \\
t, t=1,2 \ldots, T-1 ; h_{2}^{t}=0 \text { for } t=0, T\end{array}$ \\
\hline$h_{2}$ & $\begin{array}{l}I K(T+1) \text {-dimensional column vector grouped by nonnegative rela- } \\
\text { tionship level for all manufacturer/demand market combinations for } \\
t=0,1 \ldots, T\end{array}$ \\
\hline
\end{tabular}


TABLE 3. Cost functions of the manufacturers in the multiperiod supply chain network equilibrium model.

\begin{tabular}{|l|l|}
\hline $\begin{array}{l}\text { Cost } \\
\text { functions }\end{array}$ & \multicolumn{1}{|c|}{ Definition } \\
\hline$f_{i}^{t}$ & $\begin{array}{l}\text { production cost function of manufacturer } i \text { at time period } t \text {. It depends } \\
\text { not only on the manufacturer's output but also on those of the other } \\
\text { manufacturers at that time period. Hence, } f_{i}^{t}=f_{i}^{t}\left(q^{t}\right), \forall i, t .\end{array}$ \\
\hline$H_{i}^{t}$ & $\begin{array}{l}\text { inventory cost function for manufacturer } i \text { at the end of period } t, H_{i}^{t}= \\
H_{i}^{t}\left(I_{i}^{t}\right), \forall i, t .\end{array}$ \\
\hline$v_{i j l}^{t}$ & $\begin{array}{l}\text { relationship production cost functions depending on the relationship } \\
\text { level that manufacturer } i \text { wishes to achieve with retailer } j \text { when trans- } \\
\text { acting via mode } l \text { at time period } t, v_{i j l}^{t}=v_{i j l}^{t}\left(h_{i j l}^{t}\right), \forall i, j, l, t .\end{array}$ \\
\hline$v_{i k}^{t}$ & $\begin{array}{l}\text { relationship production cost functions depending on the relationship } \\
\text { level that manufacturer } i \text { wishes to achieve with consumers at demand } \\
\text { market } k \text { via the Internet at time period } t, v_{i k}^{t}=v_{i k}^{t}\left(h_{i k}^{t}\right), \forall i, k, t .\end{array}$ \\
\hline$c_{i j l}^{t}$ & $\begin{array}{l}\text { cost of transacting associated with a manufacturer and retailer pair via } \\
\text { mode } l \text { at time period } t, c_{i j l}^{t}=c_{i j l}^{t}\left(q_{i j l}^{t}, h_{i j l}^{t-1}\right), \forall i, j, l, t .\end{array}$ \\
\hline$c_{i k}^{t}$ & $\begin{array}{l}\text { cost of transacting associated with a manufacturer and demand market } \\
\text { pair } \text { via the Internet at time period } t, c_{i k}^{t}=c_{i k}^{t}\left(q_{i k}^{t}, h_{i k}^{t-1}\right), \forall i, k, t .\end{array}$ \\
\hline$r_{i j l}^{t}$ & $\begin{array}{l}\text { risk function for manufacturer } i \text { transacting with retailer } j \text { via mode } l \text { at } \\
\text { time period } t, r_{i j l}^{t}=r_{i j l}^{t}\left(q_{i j l}^{t}, h_{i j l}^{t-1}\right), \forall i, j, l, t .\end{array}$ \\
\hline$r_{i k}^{t}$ & $\begin{array}{l}\text { risk function for manufactureri transacting with demand market } k \text { via } \\
\text { the Internet at time period } t, r_{i k}^{t}=r_{i k}^{t}\left(q_{i k}^{t}, h_{i k}^{t-1}\right), \forall i, k, t .\end{array}$ \\
\hline
\end{tabular}

As mentioned in the Introduction, these decision-makers are multicriteria ones and e-commerce is also considered. We first focus on the manufacturers, then turn to the retailers, and subsequently to the consumers at demand markets.

\subsection{THE BEHAVIOR OF THE MANUFACTURERS AND THEIR OPTIMALITY CONDITIONS}

The relationship levels determined by the manufacturers are assumed to take on a value which lies in the range [0, 1]. No relationship is indicated by a level of zero, whereas, the strongest possible level of relationship is indicated by a level of one. We assume the initial value of the relationship level before transactions is equal to zero, that is, $h_{1}^{0}=h_{2}^{0}=0$. It is also necessary to interpret that because there is no incentive in the last chance to do transactions at time period $t=T$, neither the suppliers nor the buyers are willing to maintain relationship levels between them, which leads to the corresponding relationship levels all equal to zero, notably, $h_{1}^{T}=h_{2}^{T}=0$. Moreover, we note that the cost of transacting functions as well as risk cost functions listed in Table 3 are not only associated with the current product flows but also relevant to the relationship level at the preceding time period rather than the current one. 
TABLE 4. Decision variables of the retailers in the multiperiod supply chain network equilibrium model.

\begin{tabular}{|c|c|}
\hline $\begin{array}{l}\text { Decision } \\
\text { variables }\end{array}$ & Definition \\
\hline$q_{j k}^{t}$ & product shipments between retailer $j$ and demand market $k$ at time period $t$ \\
\hline$Q_{4}^{t}$ & $\begin{array}{l}J K \text {-dimensional column vector grouped by shipments transacted between } \\
\text { retailers and demand markets at time period } t \text { with component } q_{j k}^{t}\end{array}$ \\
\hline$\overline{Q_{4}}$ & $\begin{array}{l}J K T \text {-dimensional column vector grouped by shipments transacted between } \\
\text { retailers and demand markets during the entire planning horizon with com- } \\
\text { ponent } q_{j k}^{t}\end{array}$ \\
\hline$I_{j}^{t}$ & inventory quantity of retailer $j$ at the end of time period $t$ \\
\hline$Q_{5}^{t}$ & $\begin{array}{l}J \text {-dimensional column vector grouped by inventories of all retailers at the } \\
\text { end of time period } t \text { with component } I_{j}^{t}\end{array}$ \\
\hline$Q_{5}$ & $\begin{array}{l}J T \text {-dimensional column vector grouped by inventories of all retailers during } \\
\text { the entire planning horizon with component } I_{j}^{t}\end{array}$ \\
\hline$h_{j k}^{t}$ & $\begin{array}{l}\text { nonnegative relationship level between retailer } j \text { and demand market } k \text { at } \\
\text { time period } t, t=1,2 \ldots, T-1 ; h_{j k}^{t}=0 \text { for } t=0, T\end{array}$ \\
\hline$h_{3}^{t}$ & $\begin{array}{l}J K \text {-dimensional column vector grouped by nonnegative relationship level } \\
\text { for all retailer/demand market combinations at time period } t, t= \\
1,2 \ldots, T-1 ; h_{3}^{t}=0 \text { for } t=0, T\end{array}$ \\
\hline$h_{3}$ & $\begin{array}{l}J K(T+1) \text {-dimensional column vector grouped by nonnegative relationship } \\
\text { level for all retailer/demand market combinations for } t=0,1 \ldots, T\end{array}$ \\
\hline
\end{tabular}

During the entire time planning horizon, the total costs incurred by manufacturer $i$ are equal to the sum of the manufacturer's production costs, the costs of transacting, the inventory costs and the relationship production costs depending on relationship levels. His revenue, on the other hand, is the income of selling the product to both retailers and consumers at different demand markets.

Let $\rho_{1 i j l}^{t}$ denote the price charged for the product by manufacturer $i$ to retailer $j$ via mode $l$ at time period $t$ and let $\rho_{1 i k}^{t}$ denote the price charged by manufacturer $i$ for the product to demand market $k$ at time period $t$. We later discuss how to recover such prices associated with the first tier of nodes in the supply chain network. The profit maximization problem, hence, faced by manufacturer $i$ can be expressed as

$$
\begin{aligned}
\operatorname{Max} \sum_{j=1}^{J} \sum_{l=1}^{2} & \sum_{t=1}^{T} \rho_{1 i j l}^{t} q_{i j l}^{t}+\sum_{k=1}^{K} \sum_{t=1}^{T} \rho_{1 i k}^{t} q_{i k}^{t}-\sum_{t=1}^{T} f_{i}^{t}\left(q^{t}\right) \\
& -\sum_{j=1}^{J} \sum_{l=1}^{2} \sum_{t=1}^{T} c_{i j l}^{t}\left(q_{i j l}^{t}, h_{i j l}^{t-1}\right)-\sum_{k=1}^{K} \sum_{t=1}^{T} c_{i k}^{t}\left(q_{i k}^{t}, h_{i k}^{t-1}\right) \\
& -\sum_{t=1}^{T} H_{i}^{t}\left(I_{i}^{t}\right)-\sum_{k=1}^{K} \sum_{t=1}^{T} v_{i k}^{t}\left(h_{i k}^{t}\right)-\sum_{j=1}^{J} \sum_{l=1}^{2} \sum_{t=1}^{T} v_{i j l}^{t}\left(h_{i j l}^{t}\right)
\end{aligned}
$$


TABLE 5. Cost functions of the retailers in the multiperiod supply chain network equilibrium model.

\begin{tabular}{|l|l|}
\hline $\begin{array}{l}\text { Cost } \\
\text { functions }\end{array}$ & \multicolumn{1}{|c|}{ Definition } \\
\hline$c_{j}^{t}$ & $\begin{array}{l}\text { handling cost of retailer } j \text { including the display cost and the cost of } \\
\text { transacting at time period } t . \text { For the sake of generality and to enhance } \\
\text { the modeling of competition, we allow the function to depend on the } \\
\text { amounts of the product held by other retailers at that time period and, } \\
\text { therefore, } c_{j}^{t}=c_{j}^{t}\left(Q_{1}^{t}\right), \forall j, t .\end{array}$ \\
\hline$\hat{c}_{i j l}^{t}$ & $\begin{array}{l}\text { cost of transacting for retailer } j \text { transacting with manufacturer } i \text { via } \\
\text { mode } l \text { at time period } t, \hat{c}_{i j l}^{t}=\hat{c}_{i j l}^{t}\left(q_{i j l}^{t}, h_{i j l}^{t-1}\right), \forall i, j, l, t .\end{array}$ \\
\hline$H_{j}^{t}$ & $\begin{array}{l}\text { inventory cost function of retailer } j \text { at the end of period } t, H_{j}^{t}= \\
H_{j}^{t}\left(I_{j}^{t}\right), \forall j, t .\end{array}$ \\
\hline$\hat{v}_{i j l}^{t}$ & $\begin{array}{l}\text { relationship production cost functions depending on the relationship } \\
\text { level that retailer } j \text { wishes to achieve with manufacturer } i \text { via mode } l\end{array}$ \\
\hline$v_{j k}^{t}$ & $\begin{array}{l}\text { relationship production } \operatorname{cost} \text { functions depending on the relationship } \\
\text { level that retailer } j \text { wishes to achieve with consumers at demand market } \\
k \text { at time period } t, v_{j k}^{t}=v_{j k}^{t}\left(h_{j k}^{t}\right), \forall j, k, t .\end{array}$ \\
\hline$\hat{r}_{i j l}^{t}$ & $\begin{array}{l}\text { risk function for retailer } j \text { transacting with manufacturer } i \text { via mode } l \\
\text { at time period } t, \hat{r}_{i j l}^{t}=\hat{r}_{i j l}^{t}\left(q_{i j l}^{t}, h_{i j l}^{t-1}\right), \forall i, j, l, t .\end{array}$ \\
\hline$r_{j k}^{t}$ & $\begin{array}{l}\text { risk function for retailer } j \text { transacting with demand market } k \text { via the } \\
\text { Internet at time period } t, r_{j k}^{t}=r_{j k}^{t}\left(q_{j k}^{t}, h_{j k}^{t-1}\right), \forall j, k, t .\end{array}$ \\
\hline
\end{tabular}

$$
\begin{aligned}
\text { subject to: } q_{i}^{1} & =\sum_{j=1}^{J} \sum_{l=1}^{2} q_{i j l}^{1}+\sum_{k=1}^{K} q_{i k}^{1}+I_{i}^{1} \\
I_{i}^{t-1}+q_{i}^{t} & =\sum_{j=1}^{J} \sum_{l=1}^{2} q_{i j l}^{t}+\sum_{k=1}^{K} q_{i k}^{t}+I_{i}^{t}, t=2, \ldots, T
\end{aligned}
$$

and the nonnegativity constraints that:

$$
q_{i}^{t} \geq 0, \quad q_{i j l}^{t} \geq 0, q_{i k}^{t} \geq 0, I_{i}^{t} \geq 0,0 \leq h_{i j l}^{t} \leq 1, \quad 0 \leq h_{i k}^{t} \leq 1, \quad \forall i, j, k, l, t .
$$

Note that in the objective function (1.1), the first two terms represent the revenue, whereas, the subsequent six terms represent the various costs. Constraints (1.2) and (1.3) reflect that each manufacturer $i$ must satisfy the conservation of flow equation which states that at each period, the sum of product amount available for distribution at that time period and inventory of the next time period, is equal to the amount produced in that time period plus the inventory from the preceding time period. There are zero inventories assumed before the first time period and after the final time period. 
In addition to the criterion of profit maximization, each manufacturer is supposed to seek to minimize his risk generated in the transactions to the next tier of decision-makers, whether retailers or consumers at demand markets. The second criterion corresponding to risk minimization faced by manufacturer $i$, thus, can be expressed mathematically as

$$
\operatorname{Min} \sum_{j=1}^{J} \sum_{l=1}^{2} \sum_{t=1}^{T} r_{i j l}^{t}\left(q_{i j l}^{t}, h_{i j l}^{t-1}\right)+\sum_{k=1}^{K} \sum_{t=1}^{T} r_{i k}^{t}\left(q_{i k}^{t}, h_{i k}^{t-1}\right)
$$

subject to: $q_{i j l}^{t} \geq 0, q_{i k}^{t} \geq 0,0 \leq h_{i j l}^{t-1} \leq 1,0 \leq h_{i k}^{t-1} \leq 1, \forall i, j, k, l, t$.

With regard to the relationship, most of the relevant papers involved in the multicriteria decision-making considered it as a single criterion (see $[22,27,33])$. Due to the consideration of discrete time periods over a finite planning horizon, in contrast, it is reasonable to make the consideration of relationship as a factor rather than the third criterion.

Assume that manufacturer $i$ assigns a nonnegative weight $\alpha_{i j l}$ to the risk related to transacting with retailers via mode $l$ and a nonnegative weight $\alpha_{i k}$ to the risk associated with transaction to demand market $k$, respectively, according to its individual preference. The nonnegative weights measure the importance of risk and transform its value into monetary units (see [5]). The weight associated with profit maximization serves as the numeraire and is set equal to 1 . Thus, the multicriteria decision-making problem of manufacturer $i$ can be expressed as

$$
\operatorname{Max}\left[\begin{array}{l}
\sum_{j=1}^{J} \sum_{l=1}^{2} \sum_{t=1}^{T} \rho_{1 i j l}^{t} q_{i j l}^{t}+\sum_{k=1}^{K} \sum_{t=1}^{T} \rho_{1 i k}^{t} q_{i k}^{t}-\sum_{t=1}^{T} H_{i}^{t}\left(I_{i}^{t}\right) \\
-\sum_{j=1}^{J} \sum_{l=1}^{2} \sum_{t=1}^{T} c_{i j l}^{t}\left(q_{i j l}^{t}, h_{i j l}^{t-1}\right)-\sum_{k=1}^{K} \sum_{t=1}^{T} c_{i k}^{t}\left(q_{i k}^{t}, h_{i k}^{t-1}\right) \\
-\sum_{t=1}^{T} f_{i}^{t}\left(q^{t}\right)-\sum_{k=1}^{K} \sum_{t=1}^{T} v_{i k}^{t}\left(h_{i k}^{t}\right)-\sum_{j=1}^{J} \sum_{l=1}^{2} \sum_{t=1}^{T} v_{i j l}^{t}\left(h_{i j l}^{t}\right) \\
-\left(\sum_{j=1}^{J} \sum_{l=1}^{2} \sum_{t=1}^{T} \alpha_{i j l} \cdot r_{i j l}^{t}\left(q_{i j l}^{t}, h_{i j l}^{t-1}\right)+\sum_{k=1}^{K} \sum_{t=1}^{T} \alpha_{i k} \cdot r_{i k}^{t}\left(q_{i k}^{t}, h_{i k}^{t-1}\right)\right.
\end{array}\right]
$$

subject to: the conservation of flow equation (1.2) and (1.3) and non-negativity constraints (1.4).

It is necessary to assume that the continuously differentiable functions of $f_{i}^{t}$, $H_{i}^{t}, v_{i j l}^{t}$ and $v_{i k}^{t}$ are convex and monotone increasing functions with respect to their respective decision variables. The continuously differentiable functions of $c_{i j l}^{t}, c_{i k}^{t}$, $r_{i j l}^{t}$ and $r_{i k}^{t}$ are convex and monotone increasing functions with regard to $q_{i j l}^{t}, q_{i k}^{t}$, $q_{i j l}^{t}$ and $q_{i k}^{t}$, whereas they are also a family of decreasing and convex functions of the corresponding relationship levels at the preceding time period. Here, it is also 
assumed that the manufacturers compete in a noncooperative manner following Nash (see e.g., Nagurney et al. [23] and Nagurney et al. [24]), which states that each manufacturer will determine his optimal production quantity and transactions given the optimal ones of the competitors. Hence, the optimality conditions of all manufacturers simultaneously, can be compactly expressed as the following inequality $(M V I)$ :

determine $\left(q^{*}, Q_{1}^{*}, Q_{2}^{*}, Q_{3}^{*}, h_{1}^{*}, h_{2}^{*}\right) \in \Omega_{1}$ satisfying

$$
\begin{gathered}
\sum_{i=1}^{I} \sum_{t=1}^{T}\left[\frac{\partial f_{i}^{t}\left(q^{t *}\right)}{\partial q_{i}^{t}}\right] \times\left[q_{i}^{t}-q_{i}^{t *}\right]+\sum_{i=1}^{I} \sum_{j=1}^{J} \sum_{l=1}^{2} \sum_{t=1}^{T}\left[\frac{\partial c_{i j l}^{t}\left(q_{i j l}^{t *}, h_{i j l}^{(t-1) *}\right)}{\partial q_{i j l}^{t}}\right. \\
\left.+\alpha_{i j l} \cdot \frac{\partial r_{i j l}^{t}\left(q_{i j l}^{t *}, h_{i j l}^{(t-1) *}\right)}{\partial q_{i j l}^{t}}-\rho_{1 i j l}^{t *}\right] \times\left[q_{i j l}^{t}-q_{i j l}^{t *}\right]+\sum_{i=1}^{I} \sum_{k=1}^{K} \sum_{t=1}^{T}\left[\frac{\partial c_{i k}^{t}\left(q_{i k}^{t *}, h_{i k}^{(t-1) *}\right)}{\partial q_{i k}^{t}}\right. \\
\left.+\alpha_{i k} \cdot \frac{\partial r_{i k}^{t}\left(q_{i k}^{t *}, h_{i k}^{(t-1) *}\right)}{\partial q_{i k}^{t}}-\rho_{1 i k}^{t *}\right] \times\left[q_{i k}^{t}-q_{i k}^{t *}\right]+\sum_{i=1}^{I} \sum_{t=1}^{T}\left[\frac{\partial H_{i}^{t}\left(I_{i}^{t *}\right)}{\partial I_{i}^{t}}\right] \times\left[I_{i}^{t}-I_{i}^{t *}\right] \\
+\sum_{i=1}^{I} \sum_{j=1}^{J} \sum_{l=1}^{2} \sum_{t=1}^{T-1}\left[\frac{\partial c_{i j l}^{(t+1)}\left(q_{i j l}^{(t+1) *}, h_{i j l}^{t *}\right)}{\partial h_{i j l}^{t}}+\frac{\partial v_{i j l}^{t}\left(h_{i j l}^{t *}\right)}{\partial h_{i j l}^{t}}\right. \\
+\sum_{i=1}^{I} \sum_{k=1}^{K} \sum_{t=1}^{T-1}\left[\frac{\partial c_{i k}^{(t+1)}\left(q_{i k}^{(t+1) *}, h_{i k}^{t *}\right)}{\partial h_{i k}^{t}+\frac{\partial v_{i k}^{t}\left(h_{i k}^{t *}\right)}{\partial h_{i k}^{t}}+\alpha r_{i j l}^{(t+1)}\left(q_{i j l}^{(t+1) *}, h_{i j l}^{t *}\right)}\right. \\
\left.\partial h_{i j l}^{t}\right] \times\left[h_{i j l}^{t}-h_{i j l}^{t *}\right] \\
\left.+\alpha_{i j l}^{t} \cdot \frac{\partial r_{i k}^{(t+1)}\left(q_{i k}^{(t+1) *}, h_{i k}^{t *}\right)}{\partial h_{i k}^{t}}\right]
\end{gathered}
$$

where $\Omega_{1} \equiv\left\{\left(q, Q_{1}, Q_{2}, Q_{3}, h_{1}, h_{2}\right) \mid\left(q, Q_{1}, Q_{2}, Q_{3}, h_{1}, h_{2}\right) \in R_{+}^{T(2 I+2 I J+2 I K)}\right.$ and (1.2), (1.3) hold $\}$.

Referring to the above variational inequality, it can be easily seen that the feasible region is defined on a nonnegative orthant. Proposition 1.4 of Nagurney [17] indicates that this kind of variational inequality can be equivalently transformed into a nonlinear complementarity problem. Hence, the formulation of the nonlinear 
complementarity model for the manufacturer is expressed by:

$$
\begin{aligned}
& \left\{\begin{array}{l}
{\left[\frac{\partial f_{i}^{t}\left(q^{t *}\right)}{\partial q_{i}^{t}}-\lambda_{i}^{t *}\right] \times q_{i}^{t *}=0} \\
\frac{\partial f_{i}^{t}\left(q^{t *}\right)}{\partial q_{i}^{t}}-\lambda_{i}^{t *} \geq 0 \\
q_{i}^{t *} \geq 0, \forall i, t
\end{array}\right. \\
& \left\{\begin{array}{l}
\lambda_{i}^{t *}+\frac{\partial c_{i j l}^{t}\left(q_{i j l}^{t *}, h_{i j l}^{(t-1) *}\right)}{\partial q_{i j l}^{t}}+\alpha_{i j l} \cdot \frac{\partial r_{i j l}^{t}\left(q_{i j l}^{t *}, h_{i j l}^{(t-1) *}\right)}{\partial q_{i j l}^{t}}-\rho_{1 i j l}^{t *} \geq 0 \\
{\left[\begin{array}{c}
\left.\lambda_{i}^{t *}+\frac{\partial c_{i j l}^{t}\left(q_{i j l}^{t *}, h_{i j l}^{(t-1) *}\right)}{\partial q_{i j l}^{t}}+\alpha_{i j l} \cdot \frac{\partial r_{i j l}^{t}\left(q_{i j l}^{t *}, h_{i j l}^{(t-1) *}\right)}{\partial q_{i j l}^{t}}-\rho_{1 i j l}^{t *}\right] \\
\times q_{i j l}^{t *}=0
\end{array}\right.} \\
q_{i j l}^{t *} \geq 0, \forall i, j, l, t .
\end{array}\right. \\
& \left\{\begin{array}{l}
\lambda_{i}^{t *}+\frac{\partial c_{i k}^{t}\left(q_{i k}^{t *}, h_{i k}^{(t-1) *}\right)}{\partial q_{i k}^{t}}+\alpha_{i k} \cdot \frac{\partial r_{i k}^{t}\left(q_{i k}^{t *}, h_{i k}^{(t-1) *}\right)}{\partial q_{i k}^{t}}-\rho_{1 i k}^{t *} \geq 0 \\
{\left[\begin{array}{c}
\left.\lambda_{i}^{t *}+\frac{\partial c_{i k}^{t}\left(q_{i k}^{t *}, h_{i k}^{(t-1) *}\right)}{\partial q_{i k}^{t}}+\alpha_{i k} \cdot \frac{\partial r_{i k}^{t}\left(q_{i k}^{t *}, h_{i k}^{(t-1) *}\right)}{\partial q_{i k}^{t}}-\rho_{1 i k}^{t *}\right] \\
\times q_{i k}^{t *}=0
\end{array}\right.} \\
q_{i k}^{t *} \geq 0, \forall i, k, t .
\end{array}\right. \\
& \left\{\begin{array}{l}
{\left[\frac{\partial H_{i}^{t}\left(I_{i}^{t *}\right)}{\partial I_{i}^{t}}+\lambda_{i}^{t *}-\lambda_{i}^{(t+1) *}\right] \times I_{i}^{t *}=0} \\
\frac{\partial H_{i}^{t}\left(I_{i}^{t *}\right)}{\partial I_{i}^{t}}+\lambda_{i}^{t *}-\lambda_{i}^{(t+1) *} \geq 0 \\
I_{i}^{t *} \geq 0, \forall i, t=1,2 \ldots, T-1 .
\end{array}\right. \\
& \left\{\begin{array}{l}
{\left[\frac{\partial H_{i}^{T}\left(I_{i}^{T *}\right)}{\partial I_{i}^{T}}+\lambda_{i}^{T *}\right] \times I_{i}^{T *}=0} \\
\frac{\partial H_{i}^{T}\left(I_{i}^{T *}\right)}{\partial I_{i}^{T}}+\lambda_{i}^{T *} \geq 0 \\
I_{i}^{T *} \geq 0, \forall i, t=T .
\end{array}\right. \\
& \left\{\begin{array}{l}
\frac{\partial c_{i j l}^{(t+1)}\left(q_{i j l}^{(t+1) *}, h_{i j l}^{t *}\right)}{\partial h_{i j l}^{t}}+\frac{\partial v_{i j l}^{t}\left(h_{i j l}^{t *}\right)}{\partial h_{i j l}^{t}}+\alpha_{i j l} \cdot \frac{\partial r_{i j l}^{(t+1)}\left(q_{i j l}^{(t+1) *}, h_{i j l}^{t *}\right)}{\partial h_{i j l}^{t}} \geq 0 \\
{\left[\begin{array}{c}
\left.\frac{\partial c_{i j l}^{(t+1)}\left(q_{i j l}^{(t+1) *}, h_{i j l}^{t *}\right)}{\partial h_{i j l}^{t}}+\frac{\partial v_{i j l}^{t}\left(h_{i j l}^{t *}\right)}{\partial h_{i j l}^{t}}+\alpha_{i j l} \cdot \frac{\partial r_{i j l}^{(t+1)}\left(q_{i j l}^{(t+1) *}, h_{i j l}^{t *}\right)}{\partial h_{i j l}^{t}}\right] \\
\times h_{i j l}^{t *}=0
\end{array}\right.} \\
h_{i j l}^{t *} \geq 0, \forall i, j, l, t .
\end{array}\right.
\end{aligned}
$$




$$
\left\{\begin{array}{l}
\frac{\partial c_{i k}^{(t+1)}\left(q_{i k}^{(t+1) *}, h_{i k}^{t *}\right)}{\partial h_{i k}^{t}}+\frac{\partial v_{i k}^{t}\left(h_{i k}^{t *}\right)}{\partial h_{i k}^{t}}+\alpha_{i k} \cdot \frac{\partial r_{i k}^{(t+1)}\left(q_{i k}^{(t+1) *}, h_{i k}^{t *}\right)}{\partial h_{i k}^{t}} \geq 0 \\
{\left[\begin{array}{c}
\left.\frac{\partial c_{i k}^{(t+1)}\left(q_{i k}^{(t+1) *}, h_{i k}^{t *}\right)}{\partial h_{i k}^{t}}+\frac{\partial v_{i k}^{t}\left(h_{i k}^{t *}\right)}{\partial h_{i k}^{t}}+\alpha_{i k} \cdot \frac{\partial r_{i k}^{(t+1)}\left(q_{i k}^{(t+1) *}, h_{i k}^{t *}\right)}{\partial h_{i k}^{t}}\right] \\
\times h_{i k}^{t *}=0
\end{array}\right.} \\
h_{i k}^{t *} \geq 0, \forall i, k, t .
\end{array}\right.
$$

It is worth noting that $\lambda_{i}^{t}$ is the Lagrange multiplier associated with constraints (1.2) and (1.3) for manufacturer $i$ at time period $t$. Such a Lagrange multiplier also has an interpretation as a shadow price.

The economic interpretations of the above nonlinear complementarity conditions are now highlighted.

From condition (1.8) we can see that, if manufacturer $i$ produces a positive amount of the product at time period $t$, then his marginal production cost should be equal to the minimum supply cost that he is willing to pay for a unit of the product at time period $t$. Otherwise, manufacturer $i$ will produce zero volume of the product at that time period.

Condition (1.9) states that, if there is a positive shipments of the product transacted either in a classical manner or via the Internet from manufacturer $i$ to retailer $j$ at time period $t$, then the sum of his minimum supply cost, marginal cost of transacting (relevant to the quantity of product transaction) and weighted marginal risk cost (relevant to the quantity of product transaction) must be equal to the price that retailer $j$ is willing to pay for a unit product at time period $t$. Otherwise, there will be zero volume of the product flow between the particular manufacturer and retailer pair at time period $t$. Condition (1.10) has a similar interpretation.

It can be shown from conditions (1.11) and (1.12) that, for each manufacturer, the marginal inventory cost plus the minimum supply cost at time period $t$ does not exceed the minimum supply cost at the next time period $(t+1)$. Otherwise he will not stock any product at period $t$

Furthermore, conditions (1.13) and (1.14) note that if there is a positive level of relationship, then the marginal relationship production cost (relevant to the relationship level at the preceding time period) of establishing relationship level is equal to the marginal cost of transacting (relevant to the relationship level at the preceding time period) plus the weighted marginal cost (relevant to the relationship level at the preceding time period).

\subsection{THE BEHAVIOR OF THE RETAILERS AND THEIR OPTIMALITY CONDITIONS}

The retailers, in turn, also have to bear some costs to establish and maintain relationship levels with manufacturers and consumers. These relationship levels 
are assumed to be nonnegative and to take on a value from 0 to 1 . As what we do in section 1.1, we also observe that the cost of transacting functions as well as risk cost functions listed in Table 5 are relative to not only the current product flows but also the relationship level at the preceding time period rather than the current one. Similarly, it is also worth noting that $h_{1}^{0}, h_{2}^{0}, h_{1}^{T}$ and $h_{2}^{T}$ are all equal to zero.

Let $\rho_{2 j k}^{t}$ denote the price charged for the product by retailer $j$ to demand market $k$ at time period $t$. As in the case of the manufacturers, we later discuss how to recover such prices associated with the second tier of nodes in the supply chain network. Then, the optimization problem of profit maximization faced by retailer $j$ can be expressed as

$$
\begin{gathered}
\operatorname{Max} \sum_{k=1}^{K} \sum_{t=1}^{T} \rho_{2 j k}^{t} q_{j k}^{t}-\sum_{i=1}^{I} \sum_{l=1}^{2} \sum_{t=1}^{T} \rho_{1 i j l}^{t} q_{i j l}^{t}-\sum_{t=1}^{T} c_{j}^{t}\left(Q_{1}^{t}\right) \\
-\sum_{i=1}^{I} \sum_{l=1}^{2} \sum_{t=1}^{T} \hat{c}_{i j l}^{t}\left(q_{i j l}^{t}, h_{i j l}^{t-1}\right)-\sum_{k=1}^{K} \sum_{t=1}^{T} c_{j k}^{t}\left(q_{j k}^{t}, h_{j k}^{t-1}\right) \\
-\sum_{t=1}^{T} H_{j}^{t}\left(I_{j}^{t}\right)-\sum_{i=1}^{I} \sum_{l=1}^{2} \sum_{t=1}^{T} \hat{v}_{i j l}^{t}\left(h_{i j l}^{t}\right)-\sum_{k=1}^{K} \sum_{t=1}^{T} v_{j k}^{t}\left(h_{j k}^{t}\right) \\
\text { subject to : } \sum_{i=1}^{I} \sum_{l=1}^{2} q_{i j l}^{1}=\sum_{k=1}^{K} q_{j k}^{1}+I_{j}^{1} \\
I_{j}^{t-1}+\sum_{i=1}^{I} \sum_{l=1}^{2} q_{i j l}^{t}=\sum_{k=1}^{K} q_{j k}^{t}+I_{j}^{t}, t=2, \ldots, T
\end{gathered}
$$

and the nonnegativity constraints:

$$
q_{i j l}^{t} \geq 0, q_{j k}^{t} \geq 0, \quad I_{j}^{t} \geq 0,0 \leq h_{i j l}^{t} \leq 1,0 \leq h_{j k}^{t} \leq 1, \forall i, j, k, l, t .
$$

The first term in the objective function (1.15) represents the revenue of retailer $j$, whereas the rest of terms represent, respectively, payouts to the manufacturers, the handling costs, the costs of transacting (from the perspective of the retailer), the relationship production costs and the inventory costs. Constraints (1.16) and (1.17) show that each retailer $j$ must satisfy the conservation of flow equation which states that at each time period, the sum of the amount obtained in that time period from manufacturers plus the inventory from the preceding period must be equal to the sum of the amount of product available for the demand markets at that time period plus the inventory at the next time period. What's more, note that $\lambda_{j}^{t}$ is the Lagrange multiplier associated with constraints (1.16) and (1.17) for retailer $j$. These Lagrange multipliers can also be interpreted as shadow prices. For further background on such a derivation, see [21]. 
In addition to the criterion of profit maximization, each retailer is supposed to be concerned with risk minimization associated with dealing with manufacturer or consumers at demand markets. Thus, the second criterion corresponding to risk minimization faced by retailer $j$ can be expressed as

$$
\operatorname{Min} \sum_{i=1}^{I} \sum_{l=1}^{2} \sum_{t=1}^{T} \hat{r}_{i j l}^{t}\left(q_{i j l}^{t}, h_{i j l}^{t-1}\right)+\sum_{k=1}^{K} \sum_{t=1}^{T} r_{j k}^{t}\left(q_{j k}^{t}, h_{j k}^{t-1}\right)
$$

subject to:

$$
q_{i j l}^{t} \geq 0, q_{j k}^{t} \geq 0, \quad 0 \leq h_{i j l}^{t-1} \leq 1, \quad 0 \leq h_{j k}^{t-1} \leq 1, \quad \forall i, j, k, l, t .
$$

As mentioned earlier, it is also reasonable to regard relationship as a factor rather than the third criterion as a result of the consideration of discrete time periods in the supply chain network. In particular, we assume that retailer $j$ assigns a nonnegative weight $\beta_{i j l}$ to the risk related to transacting with manufacturers via mode $l$ and a nonnegative weight $\beta_{j k}$ to the risk associated with transactions to demand market $k$, respectively, according to its individual preference. As in the case of the manufacturers, the weight associated with profit maximization is set equal to 1 and serves as the numeraire (see also [5]). Then the multicriteria decision-making problem of retailer $j$ can be expressed mathematically as

$$
\operatorname{Max}\left[\begin{array}{l}
\sum_{k=1}^{K} \sum_{t=1}^{T} \rho_{2 j k}^{t} q_{j k}^{t}-\sum_{i=1}^{I} \sum_{l=1}^{2} \sum_{t=1}^{T} \rho_{1 i j l}^{t} q_{i j l}^{t}-\sum_{i=1}^{I} \sum_{l=1}^{2} \sum_{t=1}^{T} \hat{c}_{i j l}^{t}\left(q_{i j l}^{t}, h_{i j l}^{t-1}\right) \\
-\sum_{k=1}^{K} \sum_{t=1}^{T} c_{j k}^{t}\left(q_{j k}^{t}, h_{j k}^{t-1}\right)-\sum_{t=1}^{T} c_{j}^{t}\left(Q_{1}^{t}\right)-\sum_{t=1}^{T} H_{j}^{t}\left(I_{j}^{t}\right) \\
-\sum_{i=1}^{I} \sum_{l=1}^{2} \sum_{t=1}^{T} \hat{v}_{i j l}^{t}\left(h_{i j l}^{t}\right)-\sum_{k=1}^{K} \sum_{t=1}^{T} v_{j k}^{t}\left(h_{j k}^{t}\right) \\
-\sum_{i=1}^{I} \sum_{l=1}^{2} \sum_{t=1}^{T} \beta_{i j l} \cdot \hat{r}_{i j l}^{t}\left(q_{i j l}^{t}, h_{i j l}^{t-1}\right)+\sum_{k=1}^{K} \sum_{t=1}^{T} \beta_{j k} \cdot r_{j k}^{t}\left(q_{j k}^{t}, h_{j k}^{t-1}\right)
\end{array}\right]
$$

subject to: conservation of flow equations (1.16) and (1.17) and non-negativity constraints (1.18).

It is assumed that the continuously differentiable functions of $c_{j}^{t}, H_{j}^{t}, \hat{v}_{i j l}^{t}$ and $v_{j k}^{t}$ are convex and monotone increasing functions with respect to their respective decision variables. The continuously differentiable functions of $\hat{c}_{i j l}^{t}, \hat{r}_{i j l}^{t}$ and $r_{j k}^{t}$ are convex and monotone increasing functions with regard to $q_{i j l}^{t}, q_{i j l}^{t}$ and $q_{j k}^{t}$, while they are also a family of decreasing and convex functions concerning the corresponding relationship levels at the preceding time period. We assume that the retailers compete in a noncooperative manner in the sense of Nash (see also Nagurney et al. [23] and Nagurney et al. [24]), then, under the above imposed assumptions on the underlying functions, the optimality conditions of all retailers 
simultaneously can be compactly expressed as the following variational inequality $(R V I)$ :

determine $\left(Q_{1}^{*}, Q_{2}^{*}, Q_{4}^{*}, h_{1}^{*}, h_{3}^{*}\right) \in \Omega_{2}$ satisfying

$$
\begin{gathered}
\sum_{i=1}^{I} \sum_{j=1}^{J} \sum_{l=1}^{2} \sum_{t=1}^{T}\left[\frac{\partial \hat{c}_{i j l}^{t}\left(q_{i j l}^{t *}, h_{i j l}^{(t-1) *}\right)}{\partial q_{i j l}^{t}}+\frac{\partial c_{j}^{t}\left(Q_{1}^{t *}\right)}{\partial q_{i j l}^{t}}+\rho_{1 i j l}^{t *}\right. \\
\left.+\beta_{i j l} \cdot \frac{\partial \hat{r}_{i j l}^{t}\left(q_{i j l}^{t *}, h_{i j l}^{(t-1) *}\right)}{\partial q_{i j l}^{t}}\right] \times\left[q_{i j l}^{t}-q_{i j l}^{t *}\right]+\sum_{j=1}^{J} \sum_{k=1}^{K} \sum_{t=1}^{T}\left[\frac{\partial c_{j k}^{t}\left(q_{j k}^{t *}, h_{j k}^{(t-1) *}\right)}{\partial q_{j k}^{t}}\right. \\
\left.+\beta_{j k} \cdot \frac{\partial r_{j k}^{t}\left(q_{j k}^{t *}, h_{j k}^{(t-1) *}\right)}{\partial q_{j k}^{t}}-\rho_{2 j k}^{t *}\right] \times\left[q_{j k}^{t}-q_{j k}^{t *}\right] \\
+\sum_{j=1}^{J} \sum_{t=1}^{T}\left[\frac{\partial H_{j}^{t}\left(I_{j}^{t *}\right)}{\partial I_{j}^{t}}\right] \times\left[I_{j}^{t}-I_{j}^{t *}\right]+\sum_{i=1}^{I} \sum_{j=1}^{J} \sum_{l=1}^{2} \sum_{t=1}^{T-1}\left[\frac{\partial \hat{c}_{i j l}^{t+1}\left(q_{i j l}^{(t+1) *}, h_{i j l}^{t *}\right)}{\partial h_{i j l}^{t}}\right. \\
+\frac{\partial \hat{v}_{i j l}^{t}\left(h_{i j l}^{t *}\right)}{\left.\partial h_{i j l}^{t}+\beta_{i j l} \cdot \frac{\partial \hat{r}_{i j l}^{t+1}\left(q_{i j l}^{(t+1) *}, h_{i j l}^{(t+1) *}\right)}{\partial h_{i j l}^{t}}\right] \times\left[h_{i j l}^{t}-h_{i j l}^{t *}\right]} \\
+\sum_{j=1}^{J} \sum_{k=1}^{K} \sum_{t=1}^{T-1}\left[\frac{\partial c_{j k}^{t+1}\left(q_{j k}^{(t+1) *}, h_{j k}^{t *}\right)}{\partial h_{j k}^{t}}+\frac{\partial v_{j k}^{t}\left(h_{j k}^{t *}\right)}{\partial h_{j k}^{t}}\right. \\
+\beta_{j k}^{t+1} \cdot \frac{\left.\partial q_{j k}^{(t+1) *}, h_{j k}^{t *}\right)}{\partial h_{j k}^{t}} \times\left[h_{j k}^{t}-h_{j k}^{t *}\right] \geq 0 \\
\forall\left(Q_{1}, Q_{2}, Q_{4}, h_{1}, h_{3}\right) \in \Omega_{2}
\end{gathered}
$$

where $\Omega_{2} \equiv\left\{\left(Q_{1}, Q_{2}, Q_{4}, h_{1}, h_{3}\right) \mid\left(Q_{1}, Q_{2}, Q_{4}, h_{1}, h_{3}\right) \in R_{+}^{T(J+2 I J+2 J K)}\right.$ and (1.16), (1.17) hold\}. As the space is limited, the nonlinear complementarity conditions equivalent to the above variational inequality and their economic interpretations similar with those of the manufacturers are omitted here.

\subsection{The CONSUMERS AT The DEMAND MARKETS AND EQUILIBRIUM CONDITIONS}

We now describe the behavior of the consumers at different demand markets, who take into account in making their consumption decisions not only the charged price by the sellers but also the cost of transacting associated with obtaining the product from their perspective. 
Let $\hat{c}_{j k}^{t}$ denote the cost of transacting associated with demand market $k$ obtaining the product from retailer $j$ at time period $t$, which is assumed to be continuous and of the general form: $\hat{c}_{j k}^{t}=\hat{c}_{j k}^{t}\left(q_{j k}^{t}, h_{j k}^{t-1}\right), \forall j, k, t$. Hence, the cost of transacting, from the perspective of the consumers, depends on the current volume of the product transacted as well as the level of relationship formed at the preceding time period.

Let $\hat{c}_{i k}^{t}$ denote the cost of transacting associated with obtaining the product electronically from manufacturer $i$ by the consumers at demand market $k$ at time period $t$, where we assume that it is also continuous and of the general form: $\hat{c}_{i k}^{t}=\hat{c}_{i k}^{t}\left(q_{i k}^{t}, h_{i k}^{t-1}\right), \forall i, k, t$.

Denote the demand of the product at demand market $k$ at time period $t$ by $d_{k}^{t}$ and assume, as given, the continuous function: $d_{k}^{t}=d_{k}^{t}\left(\rho_{3}^{t}\right), \forall k, t$. Here, $\rho_{3}^{t}$ is the $o$-dimensional column vector with the component of $\rho_{3 k}^{t}$ which denotes the price of demand market $k$ for obtaining the product at time period $t$.

The convex and continuous functions $\hat{c}_{j k}^{t}$ and $\hat{c}_{i k}^{t}$ are monotone increasing functions concerning shipments of $q_{j k}^{t}$ and $q_{i k}^{t}$, respectively, but they are also monotone decreasing functions regarding the corresponding relationship levels at the preceding time period. In addition, the function, $d_{k}^{t}$, is monotone decreasing with respect to the price $\rho_{3}^{t}$. Hence, the equilibrium conditions for consumers at demand market $k$ take the following form: for all retailers, $j=1,2 \ldots, J$ :

$$
\rho_{2 j k}^{t *}+\hat{c}_{j k}^{t}\left(q_{j k}^{t *}, h_{j k}^{(t-1) *}\right)\left\{\begin{array}{l}
=\rho_{3 k}^{t *}, \text { if } q_{j k}^{t *}>0, \\
\geq \rho_{3 k}^{t *}, \text { if } q_{j k}^{t *}=0,
\end{array}\right.
$$

and for all manufacturers, $i=1,2 \ldots, I$ :

$$
\rho_{1 i k}^{t *}+\hat{c}_{i k}^{t}\left(q_{i k}^{t *}, h_{i k}^{(t-1) *}\right)\left\{\begin{array}{l}
=\rho_{3 k}^{t *}, \text { if } q_{i k}^{t *}>0, \\
\geq \rho_{3 k}^{t *}, \text { if } q_{i k}^{t *}=0 .
\end{array}\right.
$$

In addition, we must have that:

$$
d_{k}^{t}\left(\rho_{3}^{t *}\right)\left\{\begin{array}{l}
=\sum_{j=1}^{J} q_{j k}^{t *}+\sum_{i=1}^{I} q_{i k}^{t *}, \text { if } \rho_{3 k}^{t *}>0 \\
\leq \sum_{j=1}^{J} q_{j k}^{t *}+\sum_{i=1}^{I} q_{i k}^{t *}, \text { if } \rho_{3 k}^{t *}=0 .
\end{array}\right.
$$

Conditions (1.22) state that, in equilibrium, the consumers at demand market $k$ will purchase the product from retailer $j$ at time period $t$, if the price charged by retailer $j$ plus the cost of transacting (from the perspective of the consumers) does not exceed the price that the consumers are willing to pay at time period $t$. Conditions (1.23) state the analogue, but for the case of electronic transactions with the manufacturers. On the other hand, conditions (1.24) state that if the 
equilibrium price the consumers are willing to pay for the product is positive, then the quantity of product consumed at demand market $k$ at time period $t$ is precisely equal to the demand for the product at the same time period.

These conditions correspond to the well-known spatial price equilibrium conditions $(c f .[6,17])$ and also have been used in various supply chain network equilibrium problems (e.g., [23]). Clearly, conditions (1.22), (1.23) and (1.24) must hold for all demand markets and can be formulated as a variational inequality $(D V I)$, given by $(e . g .,[20])$ :

determine $\left(Q_{2}^{*}, Q_{4}^{*}, \rho_{3}^{*}\right) \in R_{+}^{T(J K+I K+K)}$ satisfying

$$
\begin{aligned}
\sum_{i=1}^{I} \sum_{k=1}^{K} \sum_{t=1}^{T}\left[\rho_{1 i k}^{t *}+\hat{c}_{i k}^{t}\left(q_{i k}^{t *}, h_{i k}^{(t-1) *}\right)-\rho_{3 k}^{t *}\right] \times\left[q_{i k}^{t}-q_{i k}^{t *}\right] \\
+\sum_{k=1}^{K} \sum_{j=1}^{J} \sum_{t=1}^{T}\left[\rho_{2 j k}^{t *}+\hat{c}_{j k}^{t}\left(q_{j k}^{t *}, h_{j k}^{(t-1) *}\right)-\rho_{3 k}^{t *}\right] \times\left[q_{j k}^{t}-q_{j k}^{t *}\right] \\
+\sum_{k=1}^{K} \sum_{t=1}^{T}\left[\sum_{j=1}^{J} q_{j k}^{t *}+\sum_{i=1}^{I} q_{i k}^{t *}-d_{k}^{t}\left(\rho_{3}^{t *}\right)\right] \times\left[\rho_{3 k}^{t}-\rho_{3 k}^{t *}\right] \geq 0 \\
\forall\left(Q_{2}, Q_{4}, \rho_{3}\right) \in R_{+}^{T(J K+I K+K)} .
\end{aligned}
$$

\subsection{The EqUiLibrium CONDITIONS OF THE SUPPLY CHAIN NETWORK}

Definition 1.1 (multiperiod supply chain network equilibrium with electronic commerce and multicriteria decision-making). The equilibrium state of the multiperiod supply chain network equilibrium with electronic commerce and multicriteria decision-making is one where the product flows between three tiers of the decision-makers coincide and the product outputs, shipments, inventories, relationship levels and prices satisfy the sum of the optimality conditions $(M V I),(R V I)$, and the equilibrium conditions $(D V I)$.

The equilibrium state is equivalent to the following:

Theorem 1.2 (variational inequality formulation). In terms of introducing the vector of $X=\left(q, Q_{12345}, h_{123}, \rho_{3}\right)$ where $Q_{12345}=\left(Q_{1}, Q_{2}, Q_{3}, Q_{4}, Q_{5}\right)$ and $h_{123}=\left(h_{1}, h_{2}, h_{3}\right)$, the equilibrium conditions governing the multiperiod supply chain network equilibrium with electronic commerce and multicriteria decisionmaking according to Definition 1.1 are equivalent to the solution of the variational inequality problem $(S V I)$ given by:

determine $X^{*}=\left(q^{*}, Q_{12345}^{*}, h_{123}^{*}, \rho_{3}^{*}\right) \in \Omega$ satisfying 


$$
\begin{aligned}
& \sum_{i=1}^{I} \sum_{t=1}^{T}\left[\frac{\partial f_{i}^{t}\left(q^{t *}\right)}{\partial q_{i}^{t}}\right] \times\left[q_{i}^{t}-q_{i}^{t *}\right]+\sum_{i=1}^{I} \sum_{j=1}^{J} \sum_{l=1}^{2} \sum_{t=1}^{T}\left[\frac{\partial c_{i j l}^{t}\left(q_{i j l}^{t *}, h_{i j l}^{(t-1) *}\right)}{\partial q_{i j l}^{t}}\right. \\
& +\frac{\partial c_{j}^{t}\left(Q_{1}^{t *}\right)}{\partial q_{i j l}^{t}}+\frac{\partial \hat{c}_{i j l}^{t}\left(q_{i j l}^{t *}, h_{i j l}^{(t-1) *}\right)}{\partial q_{i j l}^{t}}+\alpha_{i j l} \cdot \frac{\partial r_{i j l}^{t}\left(q_{i j l}^{t *}, h_{i j l}^{(t-1) *}\right)}{\partial q_{i j l}^{t}} \\
& \left.+\beta_{i j l} \cdot \frac{\partial \hat{r}_{i j l}^{t}\left(q_{i j l}^{t *}, h_{i j l}^{(t-1) *}\right)}{\partial q_{i j l}^{t}}\right] \times\left[q_{i j l}^{t}-q_{i j l}^{t *}\right]+\sum_{i=1}^{I} \sum_{k=1}^{K} \sum_{t=1}^{T}\left[\frac{\partial c_{i k}^{t}\left(q_{i k}^{t *}, h_{i k}^{(t-1) *}\right)}{\partial q_{i k}^{t}}\right. \\
& \left.+\hat{c}_{i k}^{t}\left(q_{i k}^{t *}, h_{i k}^{(t-1) *}\right)+\alpha_{i k} \cdot \frac{\partial r_{i k}^{t}\left(q_{i k}^{t *}, h_{i k}^{(t-1) *}\right)}{\partial q_{i k}^{t}}-\rho_{3 k}^{t *}\right] \times\left[q_{i k}^{t}-q_{i k}^{t *}\right] \\
& +\sum_{i=1}^{I} \sum_{t=1}^{T}\left[\frac{\partial H_{i}^{t}\left(I_{i}^{t *}\right)}{\partial I_{i}^{t}}\right] \times\left[I_{i}^{t}-I_{i}^{t *}\right] \\
& +\sum_{j=1}^{J} \sum_{t=1}^{T}\left[\frac{\partial H_{j}^{t}\left(I_{j}^{t *}\right)}{\partial I_{j}^{t}}\right] \times\left[I_{j}^{t}-I_{j}^{t *}\right]+\sum_{k=1}^{K} \sum_{j=1}^{J} \sum_{t=1}^{T}\left[\frac{\partial c_{j k}^{t}\left(q_{j k}^{t *}, h_{j k}^{(t-1) *}\right)}{\partial q_{j k}^{t}}\right. \\
& \left.+\hat{c}_{j k}^{t}\left(q_{j k}^{t *}, h_{j k}^{(t-1) *}\right)+\beta_{j k} \cdot \frac{\partial r_{j k}^{t}\left(q_{j k}^{t *}, h_{j k}^{(t-1) *}\right)}{\partial q_{j k}^{t}}-\rho_{3 k}^{t *}\right] \times\left[q_{j k}^{t}-q_{j k}^{t *}\right] \\
& +\sum_{i=1}^{I} \sum_{j=1}^{J} \sum_{l=1}^{2} \sum_{t=1}^{T-1}\left[\frac{\partial c_{i j l}^{(t+1)}\left(q_{i j l}^{(t+1) *}, h_{i j l}^{t *}\right)}{\partial h_{i j l}^{t}}+\frac{\partial v_{i j l}^{t}\left(h_{i j l}^{t *}\right)}{\partial h_{i j l}^{t}}\right. \\
& +\frac{\partial \hat{c}_{i j l}^{(t+1)}\left(q_{i j l}^{(t+1) *}, h_{i j l}^{t *}\right)}{\partial h_{i j l}^{t}}+\alpha_{i j l} \cdot \frac{\partial r_{i j l}^{(t+1)}\left(q_{i j l}^{(t+1) *}, h_{i j l}^{t *}\right)}{\partial h_{i j l}^{t}}+\frac{\partial \hat{v}_{i j l}^{t}\left(h_{i j l}^{t *}\right)}{\partial h_{i j l}^{t}} \\
& \left.+\beta_{i j l} \cdot \frac{\partial \hat{r}_{i j l}^{(t+1)}\left(q_{i j l}^{(t+1) *}, h_{i j l}^{t *}\right)}{\partial h_{i j l}^{t}}\right] \times\left[h_{i j l}^{t}-h_{i j l}^{t *}\right]+\sum_{i=1}^{I} \sum_{k=1}^{K} \sum_{t=1}^{T-1}\left[\frac{\partial c_{i k}^{(t+1)}\left(q_{i k}^{(t+1) *}, h_{i k}^{t *}\right)}{\partial h_{i k}^{t}}\right. \\
& \left.+\frac{\partial v_{i k}^{t}\left(h_{i k}^{t *}\right)}{\partial h_{i k}^{t}}+\alpha_{i k} \cdot \frac{\partial r_{i k}^{(t+1)}\left(q_{i k}^{(t+1) *}, h_{i k}^{t *}\right)}{\partial h_{i k}^{t}}\right] \times\left[h_{i k}^{t}-h_{i k}^{t *}\right] \\
& +\sum_{j=1}^{J} \sum_{k=1}^{K} \sum_{t=1}^{T-1}\left[\frac{\partial c_{j k}^{(t+1)}\left(q_{j k}^{(t+1) *}, h_{j k}^{t *}\right)}{\partial h_{j k}^{t}}+\frac{\partial v_{j k}^{t}\left(h_{j k}^{t *}\right)}{\partial h_{j k}^{t}}+\beta_{j k} \cdot \frac{\partial r_{j k}^{(t+1)}\left(q_{j k}^{(t+1) *}, h_{j k}^{t *}\right)}{\partial h_{j k}^{t}}\right] \\
& \times\left[h_{j k}^{t}-h_{j k}^{t *}\right]+\sum_{k=1}^{K} \sum_{t=1}^{T}\left[\sum_{j=1}^{n} q_{j k}^{t *}+\sum_{i=1}^{m} q_{i k}^{t *}-d_{k}^{t}\left(\rho_{3}^{t *}\right)\right] \times\left[\rho_{3 k}^{t}-\rho_{3 k}^{t *}\right] \geq 0
\end{aligned}
$$

$\forall X \in \Omega$ where 
$\Omega \equiv\left\{\left(q, Q_{12345}, h_{123}, \rho_{3}\right) \mid\left(q, Q_{12345}, h_{123}, \rho_{3}\right) \in R_{+}^{T(2 I+2 I J+2 I K+2 J K+J+K)} ;\right.$ and $(1.2),(1.3),(1.16),(1.17)$ hold $\}$.

For easy reference in the subsequent sections, variational inequality $(S V I)$ can be rewritten in standard variational inequality form as follows: determine $X^{*} \in \Omega$ satisfying:

$$
\left\langle F\left(X^{*}\right), \quad X-X^{*}\right\rangle \geq 0, \forall X \in \Omega .
$$

where

$$
F(X)=\left(F_{i t}, F_{i j l t}, F_{i k t}, F_{H_{i t}}, F_{j k l t}, F_{H_{j t}}, F_{h_{i j l t}}, F_{h_{i k t}}, F_{h_{j k l t}}, F_{k t}\right)
$$

for

$$
i=1,2 \ldots, I ; j=1,2 \ldots, J ; k=1,2 \ldots, K ; l=1,2 ; t=1,2 \ldots, T
$$

and the specific components of $F$ are given by the function terms preceding the multiplication signs in $(S V I)$. The term $\langle\cdot, \cdot\rangle$ denotes the inner product in $N$ dimensional Euclidean space.

We now describe how to recover the manufacturers' equilibrium prices, $\rho_{1 i j l}^{t *}$ and $\rho_{1 i k}^{t *}$, and the retailers' equilibrium prices, $\rho_{2 j k}^{t *}$, from the nonlinear complementarity conditions which are equivalent to the corresponding variational inequality. First note that from (1.9), we have that (as already discussed briefly) if $q_{i j l}^{t *}>0$, then the price

$$
\rho_{1 i j l}^{t *}=\left[\lambda_{i}^{t *}+\frac{\partial c_{i j l}^{t}\left(q_{i j l}^{t *}, h_{i j l}^{(t-1) *}\right)}{\partial q_{i j l}^{t}}+\alpha_{i j l} \cdot \frac{\partial r_{i j l}^{t}\left(q_{i j l}^{t *}, h_{i j l}^{(t-1) *}\right)}{\partial q_{i j l}^{t}}\right]
$$

or, equivalently to the following equation from the nonlinear complementarity conditions corresponding to the variational inequality $(R V I)$,

$$
\rho_{1 i j l}^{t *}=\left[\lambda_{j}^{t *}-\frac{\partial \hat{c}_{i j l}^{t}\left(q_{i j l}^{t *}, h_{i j l}^{(t-1) *}\right)}{\partial q_{i j l}^{t}}-\frac{\partial c_{j}^{t}\left(Q_{1}^{t *}\right)}{\partial q_{i j l}^{t}}-\beta_{i j l} \cdot \frac{\partial \hat{r}_{i j l}^{t}\left(q_{i j l}^{t *}, h_{i j l}^{(t-1) *}\right)}{\partial q_{i j l}^{t}}\right] .
$$

In addition, we can acquire the first tier prices associated with consumers at the demand market after solving variational inequality $(S V I)$ either set

$$
\rho_{1 i k}^{t *}=\left[\lambda_{i}^{t *}+\frac{\partial c_{i k}^{t}\left(q_{i k}^{t *}, h_{i k}^{(t-1) *}\right)}{\partial q_{i k}^{t}}+\alpha_{i k} \cdot \frac{\partial r_{i k}^{t}\left(q_{i k}^{t *}, h_{i k}^{(t-1) *}\right)}{\partial q_{i k}^{t}}\right]
$$

for any $i, k, t$ such that $q_{i k}^{t *}>0$, or $(c f .(1.23))$ for any $q_{i k}^{t *}>0$, set

$$
\rho_{1 i k}^{t *}=\left[\rho_{3 k}^{t *}-\hat{c}_{i k}^{t}\left(q_{i k}^{t *}, h_{i k}^{(t-1) *}\right)\right] .
$$


The price $\rho_{2 j k}^{t *}$ can be obtained either from the nonlinear complementarity conditions corresponding to the variational inequality $(R V I)$,

$$
\rho_{2 j k}^{t *}=\left[\frac{\partial c_{j k}^{t}\left(q_{j k}^{t *}, h_{j k}^{(t-1) *}\right)}{\partial q_{j k}^{t}}+\beta_{i k} \cdot \frac{\partial r_{j k}^{t}\left(q_{j k}^{t *}, h_{j k}^{(t-1) *}\right)}{\partial q_{j k}^{t}}+\lambda_{j}^{t *}\right]
$$

for any $j, k, t$ such that $q_{j k}^{t *}>0$, or $(c f .(1.22))$ for any $q_{j k}^{t *}>0$, set $\rho_{2 j k}^{t *}=$ $\left[\rho_{3 k}^{t *}-\hat{c}_{j k}^{t}\left(q_{j k}^{t *}, h_{j k}^{(t-1) *}\right)\right]$.

\section{Qualitative Properties}

Before attempting to solve any variational inequality, it is important to discuss whether a solution exists. From Nagurney [16], a variational inequality admits at least one solution if the entering function $F$ is continuous, and the feasible set is compact. While $F$ in (2.1) may be not continuous, the feasible region $\Omega$ is not compact. However, it is possible to impose a weak condition on $\Omega$ to guarantee existence. Let

$$
\begin{gathered}
\Omega_{b}=\left\{\left(q, Q_{1}, Q_{2}, Q_{3}, Q_{4}, Q_{5}, h_{1}, h_{2}, h_{3}, \rho_{3}\right) \mid 0 \leq q \leq b_{0}, 0 \leq Q_{1} \leq b_{1}\right. \\
0 \leq Q_{2} \leq b_{2} ; 0 \leq Q_{3} \leq b_{3}, 0 \leq Q_{4} \leq b_{4}, 0 \leq Q_{5} \leq b_{5}, \\
\left.0 \leq \rho_{3} \leq b_{6}, 0 \leq h_{1} \leq 1,0 \leq h_{2} \leq 1,0 \leq h_{3} \leq 1\right\}
\end{gathered}
$$

where $b=\left(b_{0}, b_{1}, b_{2}, b_{3}, b_{4}, b_{5}, b_{6}\right) \geq 0$ and $q \leq b_{0}, Q_{1} \leq b_{1}, Q_{2} \leq b_{2}, Q_{3} \leq$ $b_{3}, Q_{4} \leq b_{4}, Q_{5} \leq b_{5}, \rho_{3} \leq b_{6}$ mean that $q^{t} \leq b_{0}, Q_{1}^{t} \leq b_{1}, Q_{2}^{t} \leq b_{2}, Q_{3}^{t} \leq$ $b_{3}, Q_{4}^{t} \leq b_{4}, Q_{5}^{t} \leq b_{5}, \rho_{3}^{t} \leq b_{6}$. Then, $\Omega_{b}$ is a bounded, closed convex subset of $R^{T(2 I+2 I J+2 I K+2 J K+J+K)}$. Thus, the following variational inequality:

$$
\left\langle F\left(X^{b}\right), X-X^{b}\right\rangle \geq 0, \forall X \in \Omega_{b}
$$

admits at least one solution. Therefore, following Nagurney et al. [24] we have:

Lemma 2.1. Variational inequality (1.25) admits a solution if and only if there exists $a b>0$ such that variational inequality (2.1) admits a solution in $\Omega_{b}$ with

$$
q^{b}<b_{0}, Q_{1}^{b}<b_{1}, Q_{2}^{b}<b_{2}, Q_{3}^{b}<b_{3}, Q_{4}^{b}<b_{4}, Q_{5}^{b}<b_{5}, \rho_{3}^{b}<b_{6}
$$

Theorem 2.2 (existence). Suppose that there exist positive constants $M, N, R$ with $R>M$ such that:

$$
\frac{\partial f_{i}^{t}\left(q^{t}\right)}{\partial q_{i}^{t}} \geq R, \quad \forall q \text { with } q_{i}^{t} \geq N, \quad \forall i, t .
$$




$$
\begin{array}{r}
\frac{\partial c_{i j l}^{t}\left(q_{i j l}^{t}, h_{i j l}^{t-1}\right)}{\partial q_{i j l}^{t}}+\alpha_{i j l} \cdot \frac{\partial r_{i j l}^{t}\left(q_{i j l}^{t}, h_{i j l}^{t-1}\right)}{\partial q_{i j l}^{t}}+\frac{\partial \hat{c}_{i j l}^{t}\left(q_{i j l}^{t}, h_{i j l}^{t-1}\right)}{\partial q_{i j l}^{t}} \\
+\frac{\partial c_{j}^{t}\left(Q_{1}^{t}\right)}{\partial q_{i j l}(t)}+\beta_{i j l} \cdot \frac{\partial \hat{r}_{i j l}^{t}\left(q_{i j l}^{t}, h_{i j l}^{t-1}\right)}{\partial q_{i j l}^{t}} \geq R, \\
\forall Q_{1} \text { with } q_{i j l}^{t} \geq N, \forall i, j, l, t .
\end{array}
$$

$$
\begin{array}{r}
\frac{\partial c_{i k}^{t}\left(q_{i k}^{t}, h_{i k}^{t-1}\right)}{\partial q_{i k}^{t}}+\alpha_{i k} \cdot \frac{\partial r_{i k}^{t}\left(q_{i k}^{t}, h_{i k}^{t-1}\right)}{\partial q_{i k}^{t}}+\hat{c}_{i k}^{t}\left(q_{i k}^{t}, h_{i k}^{t-1}\right) \geq R \\
\forall Q_{2} \text { with } q_{i k}^{t} \geq N, \quad \forall i, k, t
\end{array}
$$

$$
\frac{\partial H_{i}^{t}\left(I_{i}^{t}\right)}{\partial I_{i}^{t}} \geq R, \forall Q_{3} \text { with } I_{i}^{t} \geq N, \quad \forall i, t
$$

$$
\begin{aligned}
\frac{\partial c_{j k}^{t}\left(q_{j k}^{t}, h_{j k}^{t-1}\right)}{\partial q_{j k}^{t}}+\beta_{j k} \cdot \frac{\partial r_{j k}^{t}\left(q_{j k}^{t}, h_{j k}^{t-1}\right)}{\partial q_{j k}^{t}}+\hat{c}_{j k}^{t}\left(q_{j k}^{t}, h_{j k}^{t-1}\right) \geq R, \\
\forall Q_{4} \text { with } q_{j k}^{t} \geq N, \forall j, k, t .
\end{aligned}
$$

$$
\begin{aligned}
& \frac{\partial H_{j}^{t}\left(I_{j}^{t}\right)}{\partial I_{j}^{t}} \geq R, \quad \forall Q_{5} \text { with } I_{j}^{t} \geq N, \quad \forall j, t . \\
& d_{k}^{t}\left(\rho_{3}^{t}\right) \leq N, \quad \forall \rho_{3} \text { with } \rho_{3 k}^{t}>M, \quad \forall k, t .
\end{aligned}
$$

Then variational inequality (1.25) admits at least one solution.

Proof. Follows using analogous arguments as the proof of existence for Theorem 2 in Hammond and Beullens [7].

Choose $b_{0}=b_{1}=b_{2}=b_{3}=b_{4}=b_{5}=b>N, b_{6}>N_{1}$ where $N_{1}=$ $\max Q_{4} \leq b, 0 \leq h_{3} \leq 1\left\{\hat{c}_{j k}^{t}\left(q_{j k}^{t}, h_{j k}^{t-1}\right)\right\}$. If it can be proved $q^{b}<b_{0}, Q_{1}^{b}<b_{1}, Q_{2}^{b}<$ $b_{2}, Q_{3}^{b}<b_{3}, Q_{4}^{b}<b_{4}, Q_{5}^{b}<b_{5}, \quad \rho_{3}^{b}<b_{6}$ respectively, then by Lemma 2.1, it is possible to establish the existence of solution to inequality (1.25).

(1) Suppose that there exists a manufacturer denoted by $i$ at a certain time period $t$ such that $q_{i}^{t, b}=b>N$. This would require $\partial f_{i}^{t, b}\left(q^{t, b}\right) / \partial q_{i}^{t, b} \leq 0$. This contradicts assumption (2.3).

(2) Suppose also there exists a retailer denoted by $j$ transacting with a manufacturer denoted by $i$ via the physical mode $(l=1)$ at a certain time period $t$ such that $q_{i j 1}^{t, b}=b>N$. This would require $\partial c_{i j 1}^{t, b} / \partial q_{i j 1}^{t, b}+\alpha_{i j 1} \cdot \partial r_{i j 1}^{t, b} / \partial q_{i j 1}^{t, b}+$ $\partial \hat{c}_{i j 1}^{t, b} / \partial q_{i j 1}^{t, b}+\partial c_{j}^{t, b} / \partial q_{i j 1}^{t, b}+\beta_{i j 1} \cdot \partial \hat{r}_{i j 1}^{t, b} / \partial q_{i j 1}^{t, b} \geq R$, which contradicts (2.4). Similarly, we can prove the rationality of the assumption (2.5). 
(3) Suppose also there exists a manufacturer denoted by $i$ at a certain time period $t$ such that $I_{i}^{t, b}=b>N$. This would require $\partial H_{i}^{t, b}\left(I_{i}^{t, b}\right) / \partial I_{i}^{t, b} \leq 0$. This contradicts the assumption (2.6). Similarly, we can prove the rationality of the assumption (2.8).

(4) Suppose also there exists a retailer denoted by $j$ transacting with consumers at a demand market denoted by $k$ at a certain time period $t$ such that $q_{j k}^{t, b}=b>$ $N$. This would require $R<\hat{c}_{j k}^{t, b}\left(q_{j k}^{t, b}, h_{j k}^{(t-1), b}\right) \leq \rho_{3}^{t, b}$. Inequality (1.24) would then require $\sum_{j=1}^{J} q_{j k}^{t}+\sum_{i=1}^{I} q_{i k}^{t} \leq d_{k}^{t}\left(\rho_{3}^{t}\right)$, then we can know $d_{k}^{t}\left(\rho_{3}^{t}\right)>N$. By the assumption (2.9), it follows that $\rho_{3 k}^{t, b} \leq M<R$. This contradicts (2.7).

(5) Now since we have established that $Q_{4}^{b}<b$, it follows that $\rho_{3 k}^{t, b} \leq \hat{c}_{j k}^{t}\left(q_{j k}^{t}, h_{j k}^{t-1}\right)$. From the definition of $N_{1}$, we conclude that $\rho_{3 k}^{t, b} \leq N_{1}<b_{6}$.

Under the conditions of Theorem 2.1, it is possible to construct $b_{0}, b_{1}, b_{2}, b_{3}, b_{4}, b_{5}$ and $b_{6}$ large enough so that the restricted variational inequality (2.1) will satisfy the boundedness condition (2.2). Therefore, by Lemma 2.1, there exists a solution to the original variational inequality (1.25).

The existence of the positive constants $M, N$ and $R$ is reasonable from an economics perspective.

If any of the manufacturer's production quantity at a certain time period is high, the marginal production cost would be expected to exceed some positive lower bound. If any of the product shipments between a manufacturer and retailer pair at a certain time period is large, we can expect the corresponding sum of the associated marginal cost associated with transacting, handling and weighted risk to exceed a positive lower bound.

Similarly, if any of the product flows between a manufacturer and demand market pair at a certain time period is large, we can expect the corresponding sum of the associated marginal cost of transacting and the marginal weighted risk cost to exceed a positive lower bound. When the product flow between a retailer and demand market pair at a certain time period is high, we can expect the sum of the marginal cost of transacting and the marginal weighted risk cost to be nonnegative and to exceed a lower bound.

Also, in the case where the inventory quantity of a manufacturer or a retailer at a certain time period is high, then the marginal inventory cost would be expected to exceed some positive lower bound. Moreover, at each period, when the price that consumers at a demand market have to pay is high, we can expect the demand for the product to be low at that consumer market.

Theorem 2.3 (uniqueness). Under the assumptions of cost functions mentioned earlier, the function that enters the variational inequality (1.25) has a unique solution in $\Omega$. 




FIGURE 2. The structure of the multiperiod supply chain network for examples.

Proof. Suppose that $X^{1}$ and $X^{2}$ are both solutions and $X^{1} \neq X^{2}$, then since both $X^{1}$ and $X^{2}$ are solutions, they must satisfy:

$$
\begin{array}{ll}
\left\langle F\left(X^{1}\right),\right. & \left.X-X^{1}\right\rangle \geq 0, \quad \forall X \in \Omega . \\
\left\langle F\left(X^{2}\right),\right. & \left.X-X^{2}\right\rangle \geq 0, \quad \forall X \in \Omega .
\end{array}
$$

After substituting $X^{2}$ for $X$ in (2.10) and $X^{1}$ for $X$ in (2.11) and adding the resulting inequalities, one obtains:

$$
\left\langle F\left(X^{1}\right)-F\left(X^{2}\right), X^{2}-X^{1}\right\rangle \geq 0
$$

but inequality (2.12) is in contradiction to the definition of strict monotonicity. Hence, $X^{1}=X^{2}$.

\section{NUMERICAL EXAMPLES}

In this section, we apply Lingo 9.0 to three numerical examples which have the network structure consisting of two manufacturers, two retailers, and two demand markets, with both $\mathrm{B} 2 \mathrm{~B}$ and $\mathrm{B} 2 \mathrm{C}$ transactions permitted. In addition, we considered three time periods for the planning horizon, that is, $T=3$. The structure of the multiperiod supply chain network for the examples is depicted in Figure 2. The detailed description is given below.

Example 3.1. The data for this example were constructed for easy interpretation purpose and to serve as a base line.

The production cost functions for the two manufacturers were:

$$
\begin{aligned}
& f_{1}\left(q^{t}\right)=2.5\left(q_{1}^{t}\right)^{2}+q_{1}^{t} q_{2}^{t}+2 q_{1}^{t}, \quad \forall t . \\
& f_{2}\left(q^{t}\right)=2.5\left(q_{2}^{t}\right)^{2}+q_{1}^{t} q_{2}^{t}+2 q_{2}^{t}, \quad \forall t .
\end{aligned}
$$


The costs of transacting faced by the two manufacturers when transacting with the two retailers were, respectively, given by:

$$
\begin{aligned}
& c_{i j 1}^{t}\left(q_{i j 1}^{t}, h_{i j 1}^{t-1}\right)=\left(0.5-0.3 h_{i j 1}^{t-1}\right)\left(q_{i j 1}^{t}\right)^{2}+\left(3.5-h_{i j 1}^{t-1}\right) q_{i j 1}^{t}, \quad \forall i, j, t . \\
& c_{i j 2}^{t}\left(q_{i j 2}^{t}, h_{i j 2}^{t-1}\right)=\left(0.5-0.2 h_{i j 2}^{t-1}\right)\left(q_{i j 2}^{t}\right)^{2}+\left(3-h_{i j 2}^{t-1}\right) q_{i j 2}^{t}, \quad \forall i, j, t .
\end{aligned}
$$

The costs of transacting of the two manufacturers when dealing with consumers at the two demand markets via the Internet were:

$$
c_{i k}^{t}\left(q_{i k}^{t}, h_{i k}^{t-1}\right)=\left(q_{i k}^{t}\right)^{2}+2 q_{i k}^{t}-2 h_{i k}^{t-1}, \forall i, k, t
$$

The handling cost functions of the two retailers, in turn, were given by:

$$
c_{j}^{t}\left(Q_{1}^{t}\right)=0.5\left[\sum_{i=1}^{2} \sum_{l=1}^{2} q_{i j l}^{t}\right]^{2}, \forall j, t .
$$

The costs of transacting of the two retailers when transacting with the two manufacturers via mode 1 and mode 2 were:

$$
\hat{c}_{i j l}^{t}\left(q_{i j l}^{t}, h_{i j l}^{t-1}\right)=1.5\left(q_{i j l}^{t}\right)^{2}+3 q_{i j l}^{t}-0.5 h_{i j l}^{t-1}, \quad \forall i, j, l, t .
$$

The costs of transacting for consumers at the two demand market when transacting with the two retailers were:

$$
\hat{c}_{j k}^{t}\left(q_{j k}^{t}, h_{j k}^{t}\right)=q_{j k}^{t}-h_{j k}^{t}+5, \forall j, k, t .
$$

The risk functions faced by the two manufacturers when transacting with the two retailers were, respectively, given by:

$$
\begin{aligned}
& r_{i j 1}^{t}\left(q_{i j 1}^{t}, h_{i j 1}^{t-1}\right)=\left(q_{i j 1}^{t}\right)^{2}+\left(1.5-h_{i j 1}^{t-1}\right) q_{i j 1}^{t}, \quad \forall i, j, t . \\
& r_{i j 2}^{t}\left(q_{i j 2}^{t}, h_{i j 2}^{t-1}\right)=\left(q_{i j 2}^{t}\right)^{2}+\left(2-h_{i j 2}^{t-1}\right) q_{i j 2}^{t}, \quad \forall i, j, t .
\end{aligned}
$$

The risk cost functions faced by the two retailers when transacting with the two manufacturers were:

$$
\hat{r}_{i j l}^{t}\left(q_{i j l}^{t}, h_{i j l}^{t-1}\right)=\left(q_{i j l}^{t}\right)^{2}+2 q_{i j l}^{t}-0.5 h_{i j l}^{t-1}, \quad \forall i, \quad j, l, t .
$$

The relationship production cost functions faced by the manufacturers when transacting with the retailers were given by:

$$
\begin{aligned}
& v_{i j 1}^{t}\left(h_{i j 1}^{t}\right)=10 h_{i j 1}^{t}+3, \quad \forall i, j, t=1,2 . \\
& v_{i j 2}^{t}\left(h_{i j 2}^{t}\right)=10 h_{i j 2}^{t}+1, \quad \forall i, j, t=1,2 .
\end{aligned}
$$

The inventory cost functions of the manufacturers and retailers, respectively, were given by:

$$
\begin{aligned}
& H_{i}^{t}=0.025\left(I_{i}^{t}\right)^{2}+0.5 I_{i}^{t}, \quad \forall i, t . \\
& H_{j}^{t}=0.005\left(I_{j}^{t}\right)^{2}+1, \quad \forall j, t .
\end{aligned}
$$


The demand functions at the two demand markets were:

$$
\begin{aligned}
& d_{1}\left(\rho_{3}^{t}\right)=-2 \rho_{31}^{t}-1.5 \rho_{32}^{t}+1000, \quad \forall t . \\
& d_{2}\left(\rho_{3}^{t}\right)=-2 \rho_{32}^{t}-1.5 \rho_{31}^{t}+1000, \quad \forall t .
\end{aligned}
$$

We set all other functions equal to zero (see [12,33]). Moreover, we assumed that the weights associated with the risk cost functions for the two retailers were all equal to zero.

Since this paper emphasized the impacts of e-commerce and relationship level on the decision-making of supply chain players with different weights concerning risk, in the following examples we assumed that $\alpha_{i j 1}=0$ and $\alpha_{i j 2}=1$, that is, the mode 1 was associated with risk-neutral preference of the manufacturers while the mode 2 was related to slight risk-averse preference of them. It implied that in the first example the two manufacturers were involved in profit maximization exclusively when transacting through physical mode $(l=1)$, whereas they were concerned with both profit maximization and risk minimization through electronic mode $(l=2)$.

The Lingo converged in 10145 iterations and yielded the following equilibrium pattern which was given in Table 6 .

It was easy to verify that the equilibrium conditions were satisfied with good accuracy. Note that there was a larger volume of product transacted physically than electronically in this example. As expected, we noted that the prices at the two demand markets exceeded the prices for the product at the retailer layer. This was mainly due to the fact that the prices increased as the product propagated down through the supply chain when costs accumulated. Clearly, in this example, consumers preferred to conduct their transactions directly with the manufacturers in electronic manner.

We would conduct numerous simulations by modifying manufacturers' associated weights of risk through different modes and investigate the effects on the equilibrium product transactions and product prices.

Example 3.2. Example 3.2 was constructed from Example 3.1 as follows. We kept the data as in the first example and increased the weights associated with the two manufacturers transacting with the two retailers through physical mode, that is, $\alpha_{i j 1}=\alpha_{i j 2}=1$. This meant that both manufacturers weighted the criterion of risk minimization equally to that of net revenue maximization. The Lingo converged in 1900 iterations and yielded the following equilibrium flow and price pattern which was given in Table 7 .

Note that, in comparison to the fact that the two manufacturers were riskneutral about transacting with retailers through traditionally physical mode $(l=1)$ in Example 3.1, we observed that the manufacturers were both risk-averse in Example 3.2.

From the results in Table 7, we could obtain that the volume of the product transacted physically between the two manufacturers and the two retailers decreased. However, the volume transacted electronically through Internet increased 
TABLE 6. Equilibrium solutions of Example 3.1.

\begin{tabular}{|c|c|c|c|}
\hline & $t=1$ & $t=2$ & $t=3$ \\
\hline$q_{i}^{t *}$ & $q_{1}^{1 *}=q_{2}^{1 *}=36.65$ & $\begin{array}{l}q_{1}^{2 *}=36.68 \\
q_{2}^{2 *}=36.68\end{array}$ & $\begin{array}{l}q_{1}^{3 *}=36.69 \\
q_{2}^{3 *}=36.65\end{array}$ \\
\hline$q_{i j l}^{t *}$ & $\begin{array}{l}q_{111}^{1 *}=q_{121}^{1 *}=q_{211}^{1 *} \\
\quad=q_{221}^{1 *}=3.52 \\
q_{112}^{1 *}=q_{122}^{1 *}=q_{212}^{1 *} \\
\quad=q_{222}^{1 *}=2.45\end{array}$ & $\begin{array}{l}q_{111}^{2 *}=q_{121}^{2 *}=q_{211}^{2 *} \\
\quad=q_{221}^{2 *}=3.50 \\
q_{112}^{2 *}=q_{122}^{2 *}=q_{212}^{2 *} \\
\quad=q_{222}^{2 *}=2.44\end{array}$ & $\begin{array}{l}q_{111}^{3 *}=q_{121}^{3 *}=q_{211}^{3 *} \\
\quad=q_{221}^{3 *}=3.50 \\
q_{112}^{3 *}=q_{122}^{3 *}=q_{212}^{3 *} \\
\quad=q_{222}^{3 *}=2.44\end{array}$ \\
\hline$h_{i j l}^{t *}$ & $\begin{array}{l}h_{111}^{1 *}=h_{121}^{1 *}=h_{211}^{1 *} \\
\quad=h_{221}^{1 *}=0.00 \\
h_{112}^{1 *}=h_{122}^{1 *}=h_{212}^{1 *} \\
\quad=h_{222}^{1 *}=0.00\end{array}$ & $\begin{array}{l}h_{111}^{2 *}=h_{121}^{2 *}=h_{211}^{2 *} \\
\quad=h_{221}^{2 *}=0.00 \\
h_{112}^{2 *}=h_{122}^{2 *}=h_{212}^{2 *} \\
\quad=h_{222}^{2 *}=0.00\end{array}$ & $\begin{array}{l}h_{111}^{3 *}=h_{121}^{3 *}=h_{211}^{3 *} \\
\quad=h_{221}^{3 *}=0.00 \\
h_{112}^{3 *}=h_{122}^{3 *}=h_{212}^{3 *} \\
\quad=h_{222}^{3 *}=0.00\end{array}$ \\
\hline$q_{i k}^{t *}$ & $\begin{array}{l}q_{11}^{1 *}=q_{12}^{1 *}=q_{21}^{1 *} \\
=q_{22}^{1 *}=12.35\end{array}$ & $\begin{array}{l}q_{11}^{2 *}=q_{21}^{2 *}=12.32 \\
q_{12}^{2 *}=q_{22}^{2 *}=12.46\end{array}$ & $\begin{array}{l}q_{11}^{3 *}=q_{12}^{3 *}=12.41 \\
q_{21}^{3 *}=q_{22}^{3 *}=12.34\end{array}$ \\
\hline$h_{i k}^{t *}$ & $\begin{array}{l}h_{11}^{1 *}=h_{21}^{1 *}=1.00 \\
h_{12}^{1 *}=h_{22}^{1 *}=0.91\end{array}$ & $\begin{array}{l}h_{11}^{2 *}=h_{12}^{2 *}=1.00 \\
h_{21}^{2 *}=h_{22}^{2 *}=0.17\end{array}$ & $\begin{array}{l}h_{11}^{3 *}=h_{12}^{3 *}=h_{21}^{3 *} \\
\quad=h_{22}^{3 *}=0.00\end{array}$ \\
\hline$I_{i}^{t *}$ & $\begin{array}{l}I_{1}^{1 *}=0.00 \\
I_{1}^{2 *}=0.00\end{array}$ & $\begin{array}{l}I_{2}^{1 *}=0.00 \\
I_{2}^{2 *}=0.00\end{array}$ & $\begin{array}{l}I_{1}^{3 *}=0.00 \\
I_{2}^{3 *}=0.00\end{array}$ \\
\hline$q_{j k}^{t *}$ & $\begin{array}{l}q_{11}^{1 *}=q_{12}^{1 *}=5.84 \\
q_{21}^{1 *}=q_{22}^{1 *}=5.81\end{array}$ & $\begin{array}{l}q_{11}^{2 *}=q_{21}^{2 *}=6.25 \\
q_{12}^{2 *}=q_{22}^{2 *}=5.95\end{array}$ & $\begin{array}{l}q_{11}^{3 *}=q_{22}^{3 *}=6.17 \\
q_{12}^{3 *}=q_{21}^{3 *}=5.75\end{array}$ \\
\hline$h_{j k}^{t *}$ & $\begin{array}{l}h_{11}^{1 *}=h_{21}^{1 *}=0.92 \\
h_{12}^{1 *}=h_{22}^{1 *}=0.00\end{array}$ & $\begin{array}{l}h_{11}^{2 *}=h_{22}^{2 *}=0.43 \\
h_{12}^{2 *}=h_{21}^{2 *}=0.00\end{array}$ & $\begin{array}{c}h_{11}^{3 *}=h_{22}^{3 *}=h_{12}^{3 *} \\
=h_{21}^{3 *}=0.00\end{array}$ \\
\hline$I_{j}^{t *}$ & $I_{1}^{1 *}=I_{2}^{1 *}=0.30$ & $I_{1}^{2 *}=I_{2}^{2 *}=0.00$ & $I_{1}^{3 *}=I_{2}^{3 *}=0.00$ \\
\hline$\rho_{1 i j l}^{t *}$ & $\begin{array}{c}\rho_{1111}^{1 *}=\rho_{1121}^{1 *}=\rho_{1211}^{1 *} \\
=\rho_{1221}^{1 *}=228.94 \\
\rho_{1112}^{1 *}=\rho_{1122}^{1 *}=\rho_{1212}^{1 *} \\
=\rho_{1222}^{1 *}=234.28\end{array}$ & $\begin{array}{c}\rho_{1111}^{2 *}=\rho_{1121}^{2 *}=\rho_{1211}^{2 *} \\
=\rho_{1221}^{2 *}=229.07 \\
\rho_{1112}^{2 *}=\rho_{1122}^{2 *}=\rho_{1212}^{2 *} \\
=\rho_{1222}^{2 *}=234.39\end{array}$ & $\begin{array}{c}\rho_{1111}^{3 *}=\rho_{1121}^{3 *}=\rho_{1211}^{3 *} \\
=\rho_{1221}^{3 *}=229.05 \\
\rho_{1112}^{3 *}=\rho_{1122}^{3 *}=\rho_{1212}^{3 *} \\
=\rho_{1222}^{3 *}=234.30\end{array}$ \\
\hline$\rho_{1 i k}^{t *}$ & $\begin{array}{l}\rho_{111}^{1 *}=\rho_{112}^{1 *}=\rho_{121}^{1 *} \\
=\rho_{122}^{1 *}=261.98\end{array}$ & $\begin{array}{l}\rho_{111}^{2 *}=\rho_{121}^{2 *}=262.02 \\
\rho_{112}^{2 *}=\rho_{122}^{2 *}=262.45\end{array}$ & $\begin{array}{l}\rho_{111}^{3 *}=\rho_{112}^{3 *}=262.33 \\
\rho_{121}^{3 *}=\rho_{122}^{3 *}=261.94\end{array}$ \\
\hline$\rho_{2 j k}^{t *}$ & $\begin{array}{l}\rho_{211}^{1 *}=\rho_{212}^{1 *}=264.49 \\
\rho_{221}^{1 *}=\rho_{222}^{1 *}=264.52\end{array}$ & $\begin{array}{l}\rho_{211}^{2 *}=\rho_{212}^{2 *}=264.49 \\
\rho_{221}^{2 *}=\rho_{222}^{2 *}=264.52\end{array}$ & $\begin{array}{l}\rho_{211}^{3 *}=\rho_{212}^{3 *}=264.49 \\
\rho_{221}^{3 *}=\rho_{222}^{3 *}=264.50\end{array}$ \\
\hline$\rho_{3 k}^{t *}$ & $\rho_{31}^{1 *}=\rho_{32}^{1 *}=275.33$ & $\rho_{31}^{2 *}=\rho_{32}^{2 *}=275.19$ & $\rho_{31}^{3 *}=\rho_{32}^{3 *}=275.24$ \\
\hline
\end{tabular}


TABLE 7. Equilibrium solutions of Example 3.2.

\begin{tabular}{|c|c|c|c|}
\hline & $t=1$ & $t=2$ & $t=3$ \\
\hline$q_{i}^{t *}$ & $q_{1}^{1 *}=q_{2}^{1 *}=36.45$ & $\begin{array}{l}q_{1}^{2 *}=36.46 \\
q_{2}^{2 *}=36.44\end{array}$ & $q_{1}^{3 *}=q_{2}^{3 *}=36.44$ \\
\hline$q_{i j l}^{t *}$ & $\begin{array}{l}q_{111}^{1 *}=q_{112}^{1 *}=q_{211}^{1 *} \\
\quad=q_{212}^{1 *}=2.79 \\
q_{121}^{1 *}=q_{122}^{1 *}=q_{221}^{1 *} \\
\quad=q_{222}^{1 *}=2.76\end{array}$ & $\begin{array}{l}q_{111}^{2 *}=q_{112}^{2 *}=2.79 \\
q_{121}^{2 *}=q_{122}^{2 *}=2.76 \\
q_{211}^{2 *}=q_{212}^{2 *}=2.80 \\
q_{221}^{2 *}=q_{222}^{2 *}=2.77\end{array}$ & $\begin{array}{l}q_{111}^{3 *}=q_{112}^{3 *}=q_{211}^{3 *} \\
\quad=q_{212}^{3 *}=2.79 \\
q_{121}^{3 *}=q_{221}^{3 *}=q_{222}^{3 *} \\
\quad=q_{122}^{3 *}=2.77\end{array}$ \\
\hline$h_{i j l}^{t *}$ & $\begin{array}{l}h_{111}^{1 *}=h_{121}^{1 *}=h_{211}^{1 *} \\
\quad=h_{221}^{1 *}=0.00 \\
h_{112}^{1 *}=h_{122}^{1 *}=h_{212}^{1 *} \\
=h_{222}^{1 *}=0.00\end{array}$ & $\begin{array}{l}h_{111}^{2 *}=h_{121}^{2 *}=h_{211}^{2 *} \\
\quad=h_{221}^{2 *}=0.00 \\
h_{112}^{2 *}=h_{122}^{2 *}=h_{212}^{2 *} \\
\quad=h_{222}^{2 *}=0.00\end{array}$ & $\begin{array}{l}h_{111}^{3 *}=h_{121}^{3 *}=h_{211}^{3 *} \\
\quad=h_{221}^{3 *}=0.00 \\
h_{112}^{3 *}=h_{122}^{3 *}=h_{212}^{3 *} \\
\quad=h_{222}^{3 *}=0.00\end{array}$ \\
\hline$q_{i k}^{t *}$ & $\begin{array}{l}q_{11}^{1 *}=q_{12}^{1 *}=q_{21}^{1 *} \\
=q_{22}^{1 *}=12.67\end{array}$ & $\begin{array}{l}q_{11}^{2 *}=q_{21}^{2 *}=12.64 \\
q_{12}^{2 *}=q_{22}^{2 *}=12.68\end{array}$ & $\begin{array}{l}q_{11}^{3 *}=q_{21}^{3 *}=12.66 \\
q_{12}^{3 *}=q_{22}^{3 *}=12.65\end{array}$ \\
\hline$h_{i k}^{t *}$ & $\begin{array}{c}h_{11}^{1 *}=h_{21}^{1 *}=h_{22}^{1 *} \\
=0.00 \\
h_{12}^{1 *}=1.00\end{array}$ & $\begin{array}{l}h_{11}^{2 *}=h_{12}^{2 *}=h_{21}^{2 *} \\
\quad=h_{22}^{2 *}=0.00\end{array}$ & $\begin{array}{c}h_{11}^{3 *}=h_{12}^{3 *}=h_{21}^{3 *} \\
=h_{22}^{3 *}=0.00\end{array}$ \\
\hline$I_{i}^{t *}$ & $\begin{array}{l}I_{1}^{1 *}=0.00 \\
I_{1}^{2 *}=0.00\end{array}$ & $\begin{array}{l}I_{2}^{1 *}=0.00 \\
I_{2}^{2 *}=0.00\end{array}$ & $\begin{array}{l}I_{1}^{3 *}=0.00 \\
I_{2}^{3 *}=0.00\end{array}$ \\
\hline$q_{j k}^{t *}$ & $\begin{array}{l}q_{11}^{1 *}=q_{12}^{1 *}=5.18 \\
q_{21}^{1 *}=q_{22}^{1 *}=5.53\end{array}$ & $\begin{array}{l}q_{11}^{2 *}=q_{12}^{2 *}=5.98 \\
q_{21}^{2 *}=q_{22}^{2 *}=5.38\end{array}$ & $\begin{array}{l}q_{11}^{3 *}=q_{22}^{3 *}=5.89 \\
q_{12}^{3 *}=q_{21}^{3 *}=5.39\end{array}$ \\
\hline$h_{j k}^{t *}$ & $\begin{array}{l}h_{11}^{1 *}=h_{12}^{1 *}=0.00 \\
h_{21}^{1 *}=h_{22}^{1 *}=0.00\end{array}$ & $\begin{array}{l}h_{11}^{2 *}=h_{22}^{2 *}=0.63 \\
h_{21}^{2 *}=h_{22}^{2 *}=0.25\end{array}$ & $\begin{array}{l}h_{11}^{3 *}=h_{22}^{3 *}=h_{21}^{3 *} \\
=h_{22}^{3 *}=0.000\end{array}$ \\
\hline$I_{j}^{t *}$ & $\begin{array}{l}I_{1}^{1 *}=0.80 \\
I_{1}^{2 *}=0.00\end{array}$ & $\begin{array}{l}I_{2}^{1 *}=0.00 \\
I_{2}^{2 *}=0.29\end{array}$ & $I_{1}^{3 *}=I_{2}^{3 *}=0.00$ \\
\hline$\rho_{1 i j l}^{t *}$ & $\begin{array}{l}\rho_{1111}^{1 *}=\rho_{1112}^{1 *}=\rho_{1211}^{1 *} \\
\quad=\rho_{1212}^{1 *}=234.10 \\
\rho_{1121}^{1 *}=\rho_{1122}^{1 *}=\rho_{1221}^{1 *} \\
\quad=\rho_{1222}^{1 *}=234.02\end{array}$ & $\begin{array}{c}\rho_{1111}^{2 *}=\rho_{1112}^{2 *} \\
=233.11 \\
\rho_{1121}^{2 *}=\rho_{1122}^{2 *} \\
=234.01 \\
\rho_{1211}^{2 *}=\rho_{1212}^{2 *} \\
=234.05 \\
\rho_{1221}^{2 *}=\rho_{1222}^{2 *} \\
=233.95\end{array}$ & $\begin{array}{c}\rho_{1111}^{3 *}=\rho_{1112}^{3 *} \\
=233.01 \\
\rho_{1121}^{3 *}=\rho_{1122}^{3 *} \\
=233.94 \\
\rho_{1211}^{3 *}=\rho_{1212}^{3 *} \\
=234.01 \\
\rho_{1221}^{3 *}=\rho_{1222}^{3 *} \\
=233.94\end{array}$ \\
\hline$\rho_{1 i k}^{t *}$ & $\begin{array}{c}\rho_{111}^{1 *}=\rho_{112}^{1 *}=\rho_{121}^{1 *} \\
=\rho_{122}^{1 *}=261.64\end{array}$ & $\begin{array}{l}\rho_{111}^{2 *}=\rho_{121}^{2 *}=261.61 \\
\rho_{112}^{2 *}=\rho_{122}^{2 *}=262.26\end{array}$ & $\begin{array}{l}\rho_{111}^{3 *}=\rho_{121}^{3 *}=261.62 \\
\rho_{112}^{3 *}=\rho_{122}^{3 *}=261.59\end{array}$ \\
\hline$\rho_{2 j k}^{t *}$ & $\begin{array}{l}\rho_{211}^{1 *}=\rho_{212}^{1 *}=265.27 \\
\rho_{221}^{1 *}=\rho_{222}^{1 *}=264.89\end{array}$ & $\begin{array}{l}\rho_{211}^{2 *}=\rho_{212}^{2 *}=265.24 \\
\rho_{221}^{2 *}=\rho_{222}^{2 *}=264.85\end{array}$ & $\begin{array}{l}\rho_{211}^{3 *}=\rho_{212}^{3 *}=265.14 \\
\rho_{221}^{3 *}=\rho_{222}^{3 *}=264.85\end{array}$ \\
\hline$\rho_{3 k}^{t *}$ & $\rho_{31}^{1 *}=\rho_{32}^{1 *}=275.41$ & $\rho_{31}^{2 *}=\rho_{32}^{2 *}=275.22$ & $\rho_{31}^{3 *}=\rho_{32}^{3 *}=275.26$ \\
\hline
\end{tabular}


(relative to those obtained in Ex. 3.1), that is, the shortages in the physical product flows were partially compensated by electronic transactions. Given that the manufacturers were both concerned with the physical product transactions which their risk functions could demonstrate, an increase in the electronic product transactions was expected. As a result, the value of prices charged by both manufacturers increased accordingly.

One would expect that the more risk-averse preference of the manufacturers (i.e., larger, that is, higher weights of risk) would imply that the associated equilibrium value of the relationship levels involved would be reached more higher. For this example, we noted that the equilibrium relationship levels were all equal to zero, that is, the whole relationship levels among decision-makers in the supply chain network were at the lowest levels, although both manufacturers were risk-averse to the electronic transactions. Note that these results did not follow intuition that increasing of the weights of risk was expected to affect the relationship level and the behavior of decision-makers in the network and, therefore, the system.

From condition (1.13) and (1.14), we could obtain that the decision on whether to maintain the current relationship $(t=1,2)$ depended on whether the marginal relationship production cost for maintaining relationship levels was less than the sum of the marginal cost of transacting and the marginal risk cost. Under the premise that the decision-making members were not risk-neutral, if the former was less than the latter, he would choose to maintain the relationship and the corresponding relationship level was nonnegative.

In addition, both manufacturers' risk-averse preference about physical transactions resulted in an overall decrease of the amount of product supplied by the two manufacturers. It was worth noting that since the prices charged by the manufacturers to the retailers increased, the prices charged by the retailers to consumers also increased. Because consumers at the two demand markets could satisfy their demand either through the manufacturers electronically or through the retailers physically, the change in ultimate prices was insignificant.

Interestingly, the increase of weights did not change the relationship levels. It might be due to the fact that the manufacturers were more sensitive to the demand from consumers located at the two demand markets or the manufacturers were more concerned about whether it was economic to establish relationship with retailers when transacting with those through physical product flows. It might also because relationship was not one-way but two-way. If the retailers did not choose to maintain their relationship levels for the economic purpose, even though manufacturers chose, the relationship levels between them would not change in significant ways.

As to the inventory of each retailer at each time period $(t=1,2)$, it was worth noting that $I_{1}^{1 *}=0.80$ and $I_{2}^{2 *}=0.29$, which demonstrated that the difference between its production output and the total product shipments would be treated as his inventory at that time period. Similarly, we could obtain the inventory of each retailer at each time period. 
Example 3.3. We then modified Example 3.2 as follows. All the data were as in the Example 4.2 except that we increased the risk weights associated with electronic transaction, $\alpha_{i j 2}$, which were all equal to 2 . This meant that, in effect, the two manufacturers were more risk-averse to the transactions to the retailers through the Internet than that in Example 3.2. The Lingo converged in 9365 iterations and yielded the following equilibrium flow and price pattern (see Tab. 8):

Unlike Example 3.2 in which the risk weights associated with electronic transactions through mode 2 were equal to those related to physical transactions through mode 1 , both manufacturers were more risk-averse to retailers when the transactions were conducted electronically in this example. An interesting fact to note here was that even though the change in the mode of transactions appeared only with manufacturers and retailers, it affected the entire supply chain network system and the prices throughout the entire system.

From the results in Table 8, we could observe that the more risk-averse preference of both manufactures resulted in an overall decrease of the product provided by the two manufacturers. Note that there were more transactions conducted electronically than physically between the two manufacturers and the two retailers at each time period. The effect on the corresponding prices of product was the opposite. At the time period $t=2$, in contrast to relationship levels $h_{i j 1}^{2 *}$ which were all greater than zero, relationship levels $h_{i j 2}^{2 *}$ remained at zero. It might seem counterintuitive that weights of the risk were not sufficient condition to guarantee the relevant relationship levels nonnegative. As the analysis in example 3.2, however, this had the interpretation that the decision on whether to maintain the current relationship levels was dependent on whether the sum of the marginal cost of transacting and the marginal cost of risk (which were both reduced by relationship) exceeded the marginal relationship production cost for maintaining relationship levels or not.

Compared with the results in Table 7 , we obtained that product flows between the two manufacturers and the two demand markets at three time periods, $q_{i k}^{t *}$, were all larger than those obtained in Example 3.2. It might be due to the fact that the sum of the increased volume of $q_{i j 1}^{t *}$ and the decreased volume of $q_{i j 2}^{t *}$ was still greater than zero. From the equilibrium solution in Table 8, what's more, the relationship levels between the two manufacturers and the two demand markets at time period $t=2$ were all larger than those at time period $t=1$. This would result in the increasing of the cost of transacting as well as the risk costs at time period $t=2$ (which were both decreasing in the relationship levels of the preceding time period). Then, it made sense for the manufacturers to increase the amounts of their product flows related to consumers at different demand markets. On the contrary, the manufacturers increased electronic transactions relevant to consumers at time period $t=3$, which was largely the result of the decreased relationship levels between such decision-makers.

The results also showed that when the sum of the marginal inventory cost of each manufacturer or retailer and the shadow price at time period $t$ exceeded the shadow price at the next time period $(t+1)$, he would not stock any product at 
TABLE 8. Equilibrium solutions of Example 3.3.

\begin{tabular}{|c|c|c|c|}
\hline & $t=1$ & $t=2$ & $t=3$ \\
\hline$q_{i}^{t *}$ & $q_{1}^{1 *}=q_{2}^{1 *}=36.29$ & $\begin{array}{l}q_{1}^{2 *}=36.32 \\
q_{2}^{2 *}=36.32\end{array}$ & $\begin{array}{l}q_{1}^{3 *}=36.40 \\
q_{2}^{3 *}=36.41\end{array}$ \\
\hline$q_{i j l}^{t *}$ & $\begin{array}{l}q_{111}^{1 *}=q_{211}^{1 *}=3.01 \\
q_{121}^{1 *}=q_{221}^{1 *}=3.03 \\
q_{112}^{1 *}=q_{212}^{1 *}=2.20 \\
q_{122}^{1 *}=q_{222}^{1 *}=2.22\end{array}$ & $\begin{array}{l}q_{111}^{2 *}=q_{211}^{2 *}=2.98 \\
q_{112}^{2 *}=q_{212}^{2 *}=2.19 \\
q_{121}^{2 *}=q_{221}^{2 *}=3.01 \\
q_{122}^{2 *}=q_{222}^{2 *}=2.21\end{array}$ & $\begin{array}{l}q_{111}^{3 *}=q_{121}^{3 *}=q_{211}^{3 *} \\
\quad=q_{221}^{3 *}=3.33 \\
q_{112}^{3 *}=q_{122}^{3 *}=q_{212}^{3 *} \\
\quad=q_{222}^{3 *}=2.09\end{array}$ \\
\hline$h_{i j l}^{t *}$ & $\begin{array}{l}h_{111}^{1 *}=h_{121}^{1 *}=h_{211}^{1 *} \\
=h_{221}^{1 *}=0.00 \\
h_{112}^{1 *}=h_{122}^{1 *}=h_{212}^{1 *} \\
=h_{222}^{1 *}=0.00\end{array}$ & $\begin{array}{l}h_{111}^{2 *}=h_{121}^{2 *}=h_{211}^{2 *} \\
=h_{221}^{2 *}=0.95 \\
h_{112}^{2 *}=h_{122}^{2 *}=h_{212}^{2 *} \\
=h_{222}^{2 *}=0.00\end{array}$ & $\begin{array}{c}h_{111}^{3 *}=h_{121}^{3 *}=h_{211}^{3 *} \\
=h_{221}^{3 *}=0.00 \\
h_{112}^{3 *}=h_{122}^{3 *}=h_{212}^{3 *} \\
=h_{222}^{3 *}=0.00 \\
\end{array}$ \\
\hline$q_{i k}^{t *}$ & $\begin{array}{l}q_{11}^{1 *}=q_{12}^{1 *}=q_{21}^{1 *} \\
=q_{22}^{1 *}=12.92\end{array}$ & $\begin{array}{l}q_{11}^{2 *}=q_{21}^{2 *}=12.93 \\
q_{12}^{2 *}=q_{22}^{2 *}=12.98\end{array}$ & $\begin{array}{l}q_{11}^{3 *}=q_{21}^{3 *}=12.79 \\
q_{12}^{3 *}=q_{22}^{3 *}=12.82\end{array}$ \\
\hline$h_{i k}^{t *}$ & $\begin{array}{l}h_{11}^{1 *}=h_{12}^{1 *}=1.00 \\
h_{21}^{1 *}=h_{22}^{1 *}=0.87\end{array}$ & $\begin{array}{l}h_{11}^{2 *}=1.00 \\
h_{12}^{2 *}=0.00 \\
h_{21}^{2 *}=0.82 \\
h_{22}^{2 *}=0.69\end{array}$ & $\begin{array}{l}h_{11}^{3 *}=h_{12}^{3 *}=h_{21}^{3 *} \\
\quad=h_{22}^{3 *}=0.00\end{array}$ \\
\hline$I_{i}^{t *}$ & $\begin{array}{l}I_{1}^{1 *}=0.00 \\
I_{2}^{1 *}=0.00\end{array}$ & $\begin{array}{l}I_{1}^{2 *}=0.01 \\
I_{2}^{2 *}=0.06\end{array}$ & $\begin{array}{l}I_{1}^{3 *}=0.00 \\
I_{2}^{3 *}=0.00\end{array}$ \\
\hline$q_{j k}^{t *}$ & $\begin{array}{l}q_{11}^{1 *}=q_{12}^{1 *}=5.21 \\
q_{21}^{1 *}=q_{22}^{1 *}=4.97\end{array}$ & $\begin{array}{l}q_{11}^{2 *}=q_{21}^{2 *}=5.38 \\
q_{12}^{2 *}=q_{22}^{2 *}=5.29\end{array}$ & $\begin{array}{l}q_{11}^{3 *}=q_{21}^{3 *}=5.46 \\
q_{12}^{3 *}=q_{22}^{3 *}=5.37\end{array}$ \\
\hline$h_{j k}^{t *}$ & $\begin{array}{c}h_{11}^{1 *}=h_{12}^{1 *}=0.00 \\
h_{21}^{1 *}=0.99 \\
h_{22}^{1 *}=0.42\end{array}$ & $\begin{array}{c}h_{11}^{2 *}=h_{12}^{2 *}=0.00 \\
h_{21}^{2 *}=1.00 \\
h_{22}^{2 *}=0.01\end{array}$ & $\begin{array}{l}h_{11}^{3 *}=h_{12}^{3 *}=h_{21}^{3 *} \\
=h_{22}^{3 *}=0.00\end{array}$ \\
\hline$I_{j}^{t *}$ & $\begin{array}{l}I_{1}^{1 *}=0.00 \\
I_{2}^{1 *}=0.57\end{array}$ & $I_{1}^{2 *}=I_{2}^{2 *}=0.00$ & $I_{1}^{3 *}=I_{2}^{3 *}=0.00$ \\
\hline$\rho_{1 i j l}^{t *}$ & $\begin{array}{l}\rho_{1111}^{1 *}=\rho_{1121}^{1 *}=233.77 \\
\rho_{1112}^{1 *}=\rho_{1212}^{1 *}=237.78 \\
\rho_{1121}^{1 *}=\rho_{1221}^{1 *}=233.83 \\
\rho_{1122}^{1 *}=\rho_{1222}^{1 *}=237.86\end{array}$ & $\begin{array}{l}\rho_{1111}^{2 *}=\rho_{1121}^{2 *}=233.87 \\
\rho_{1112}^{2 *}=\rho_{1212}^{2 *}=237.50 \\
\rho_{1121}^{2 *}=\rho_{1221}^{2 *}=233.96 \\
\rho_{1122}^{2 *}=\rho_{1222}^{2 *}=237.97\end{array}$ & $\begin{array}{l}\rho_{1111}^{3 *}=\rho_{1121}^{3 *}=231.44 \\
\rho_{1112}^{3 *}=\rho_{1212}^{3 *}=237.76 \\
\rho_{1121}^{3 *}=\rho_{1221}^{3 *}=231.82 \\
\rho_{1122}^{3 *}=\rho_{1222}^{3 *}=237.96\end{array}$ \\
\hline$\rho_{1 i k}^{t *}$ & $\begin{array}{c}\rho_{111}^{1 *}=\rho_{112}^{1 *}=\rho_{121}^{1 *} \\
=\rho_{122}^{1 *}=261.51\end{array}$ & $\begin{array}{l}\rho_{111}^{2 *}=\rho_{121}^{2 *}=261.72 \\
\rho_{112}^{2 *}=\rho_{122}^{2 *}=261.86\end{array}$ & $\begin{array}{l}\rho_{111}^{3 *}=\rho_{121}^{3 *}=261.78 \\
\rho_{112}^{3 *}=\rho_{122}^{3 *}=261.84\end{array}$ \\
\hline$\rho_{2 j k}^{t *}$ & $\begin{array}{l}\rho_{11}^{1 *}=\rho_{12}^{1 *}=265.22 \\
\rho_{21}^{1 *}=\rho_{22}^{1 *}=265.46\end{array}$ & $\begin{array}{l}\rho_{11}^{2 *}=\rho_{12}^{2 *}=265.10 \\
\rho_{21}^{2 *}=\rho_{22}^{2 *}=265.47\end{array}$ & $\begin{array}{l}\rho_{11}^{3 *}=\rho_{12}^{3 *}=264.90 \\
\rho_{21}^{3 *}=\rho_{22}^{3 *}=265.37\end{array}$ \\
\hline$\rho_{3 k}^{t *}$ & $\rho_{31}^{1 *}=\rho_{32}^{1 *}=275.43$ & $\rho_{31}^{2 *}=\rho_{32}^{2 *}=275.27$ & $\rho_{31}^{3 *}=\rho_{32}^{3 *}=275.25$ \\
\hline
\end{tabular}


time period $t$. Similar with Example 3.2, consumers at the various demand markets could purchase product either from the manufacturers electronically or from the retailers physically, thus the consumers' willing-to-pay prices in general did not respond significantly.

In summary, such results revealed important managerial insights for supply chain decision-makers. The supply chain administrators should first evaluate the risk of the firm by using the above principles. If the firm was more concerned about risk they should try to confirm whether it was economic to develop or maintain relationship or not. If so, they should make no spare to strengthen the relationship level with their business partners since high relationship level would reduce their cost of transacting as well as risk costs. Furthermore, they should also maintain certain production capacity especially when relationship levels were high enough.

Obviously, the above examples are stylized but they demonstrate the efficacy of the model. Indeed, different input data and dimensions of the problems solved will affect the equilibrium outputs, transactions, inventories, relationship levels and price patterns. One could also explore the effects of data as well as the effects of changes in the number of manufacturers, retailers, and demand markets.

\section{Conclusion And Directions For FUture RESEARCH}

In this paper, a framework for the formulation and analysis of the multiperiod supply chain network equilibrium problem was proposed. We allowed for physical as well as electronic transactions between the various decision-makers in the presence of both B2B e-commerce and B2C e-commerce. The decision-makers were: manufacturers, retailers and consumers at different demand markets, who might compete within a tier but cooperate between tiers. We described their multicriteria decision-making behavior including the maximization of profit as well as the minimization of risk. The manufacturers and the retailers were permitted to weight their objective functions according to their individual preferences. In addition, the relationship levels were assumed to reduce not only the risk cost but also the associated cost of transacting. Consequently, the remarkable feature of the paper was the integration of e-commerce, multicriteria decision-making and the discrete time planning along with inventorying, namely, multiperiod decision-making. Compared with other relevant references, in addition, the paper regarded relationship as an influencing factor rather than the third criterion on account of considering time periods over a finite planning horizon.

We discussed behavior of the various decision-makers, established the optimality conditions for the manufacturers and the retailers, along with the equilibrium conditions, and provided the finite-dimensional variational inequality formulation. Qualitative properties of the equilibrium model, notably, the existence as well as the uniqueness under suitable assumptions on the underlying functions, were established. Finally, several illustrative examples were considered to verify the rationality of the model and obtain some managerial insight to manufacturers 
and retailers involved in different decision-making, such as producing, transacting, inventorying, establishing relationship and so on.

For further research, the model may include the consideration of different cost of transacting structures between electronic and non-electronic modes, computing risk functions and calibrating those parameters of weights associated with risk costs. Moreover, an application of the algorithm to concrete numerical examples and the continuous time planning should also be integrated into the modeling. It is the author's intention to explore such areas in future work.

Acknowledgements. Special thanks are addressed to the two anonymous Reviewers as well as the Editor for valuable comments and helpful suggestions. This research is supported by Nature Science Foundation of China (NSFC) Grant No. 11171348. The authors would like to thank Professor Jiye Han from Institute of Applied Mathematics, Chinese Academy of Sciences, China, for his helpful advice.

\section{REFERENCES}

[1] K.J. Arrow, M.D. Intrilligator, Handbook of Mathematical Economics. Elsevier, New York (1982).

[2] F. Bernstein and A. Federgruen, Pricing and replenishment stratgies in a distribution system with competing retailers. Nav. Res. Logist. 51 (2003) 409-426.

[3] P.J. Cai, The Time-Dependent Supply Chain Network Equilibrium Model. Master Thesis. National Central University, Taiwan (2003).

[4] R.H. Coase, The nature of the firm. Economica New Series 4 (1937) 386-405.

[5] J.M. Cruz, Dynamics of supply chain networks with corporate social responsibility through integrated environmental decision-making. Eur. J. Oper. Res. 184 (2008) 1005-1031.

[6] J. Dong, D. Zhang and A. Nagurney, Supply chain networks with multicriteria decisionmakers, in Transportation and Traffic Theory in the 21st Century, edited by M.A.P. Taylor. Pergamon (2002) 179-196.

[7] D. Hammond and P. Beullens, Closed-loop supply chain network equilibrium under legislation. Eur. J. Oper. Res. 183 (2007) 895-908.

[8] M.E. Johnson, Learning from toys: Lessons in managing supply chain risk from toy industry. California Management Review 43 (2001) 106-130.

[9] U. Juttner, H. Peck and M. Christopher, Supply chain risk management: Outlining and agenda for future research. Int. J. Logist.: Res. Appl. 6 (2003) 197-210.

[10] D. Kinderlehrer and G. Stampacchia, An Introduction to Variational Inequailties and Their Application. Academic Press, New York (1980).

[11] F.A. Kuglin and B.A. Rosenbaum, The Supply Chain Network@ Internet Speed. American Management Association, New York (2001).

[12] X.Q. Li, Research on The Supply Chain Supernetwork with Electronic Commerce Based on the Variational Inequality, Master Thesis. Dalian Maritime University, Dalian (2007).

[13] Z. Liu and A. Nagurney, Multiperiod competitive supply chain networks with inventorying and a transportation network equilibrium reformulation. Optimization Engineering 13 (2012) 471-503.

[14] C.F. Li, E.S. Qi, and J. Li, Dynamic equilibrium of supply chain network. J. Tianjin University 39 (2006) 274-278.

[15] D. Lucking-Reiley and D.F. Spulber, Business-to-business electronic commerce. J. Econ. Perspect. 15 (2001) 55-68.

[16] A. Nagurney, Network Economics: A Variational Inequality Approach. Kluwer Academic Publishers, Dordrecht, Netherlands (1993). 
[17] A. Nagurney, Network Economics: A Variational Inequality Approach (second and revised edition). Kluwer Academic Publishers, Dordrecht, Netherlands (1999).

[18] A. Nagurney, A multiclass, multicriteria traffic network equilibrium model. Math. Comput. Modell. 32 (2000) 393-411.

[19] A. Nagurney and J. Aronson, A general spatial price equilibrium model: formulation, solution, and computational results. J. Comput. Appl. Math. 22 (1988) 339-357.

[20] A. Nagurney and J. Dong, Supernetworks: Decision-Making for the Information Age. Edward Elgar Publishing, Cheltenham, England (2002).

[21] A. Nagurney and J. Dong, A multiclass, multicriteria traffic network equilibrium model with elastic demand. Transp. Res. B 36 (2002) 445-469.

[22] A. Nagurney, J. Dong and D. Zhang, Multicriteria spatial price networks: statics and dynamics, in Equilibrium problems and variational models, edited by P. Daniele, F. Giannessi, A. Maugeri. Springer (2000) 229-321.

[23] A. Nagurney, J. Dong and D. Zhang, A supply chain network equilibrium model. Transp. Res. Part E 38 (2002) 281-303.

[24] A. Nagurney, J. Loo, J. Dong and D. Zhang, Supply chain networks and electronic commerce: A theoretical perspective. Netnomics 4 (2002) 187-220.

[25] A. Nagurney and L.S. Nagurney, Sustainable supply chain network design: a multicriteria perspective. ISUE 3 (2010) 189-197.

[26] A. Nagurney and F. Toyasaki, Supply chain supernetworks and environmental criteria. Transp. Res. D 8 (2003) 185-213.

[27] A. Nagurney, T. Wakolbinger and Z. Li, The evolution and emergence of Integrated social and financial networks with electronic transactions: A dynamic supernetwork theory for the modeling, analysis, and computation of financial flows and relationship levels. Comput. Econ 27 (2006) 353-393.

[28] A. Norrman and U. Jansson, Ericsson's proactive supply chain risk management approach after a serious sub-supplier accident. Int. J. Phys. Distrib. Logist. Manag. 34 (2004) 434-456.

[29] G. Perakis and A. Sood, Competitive multi-period pricing for perishable products: a robust optimization approach. Math. Program. 107 (2006) 295-335.

[30] R.E. Quandt, A probabilistic abstract mode model, in Studies in travel demand VIII. Mathematica, Princeton, New Jersey (1967) 127-149.

[31] P.A. Samuelson, Spatial price equilibrium and linear programming. Am. Econ. Rev. 42 (1952) 283-303.

[32] T.J. Stewart and R.C. van den Honert, Trends in multicriteria decision-making, in Proc. of the 13th International Conference on Multiple Criteria Decision Making, Berlin (1998).

[33] T. Wakolbinger and A. Nagurney, Dynamic supernetworks for the integration of social networks and supply chains with electronic commerce: Modeling and analysis of buyer-seller relationships with computations. Netnomics 6 (2004) 153-185.

[34] O.E. Williamson, Transaction cost economics: The governance of contractual relations. J. Law Econ. 22 (1979) 233-261. 